\title{
Clinical and genetic aspects of primary ciliary dyskinesia/Kartagener syndrome
}

\author{
Margaret W. Leigh, $M D^{I}$, Jessica E. Pittman, MD ${ }^{I}$, Johnny L. Carson, PhD $D^{I}$, Thomas W. Ferkol, $M D^{2}$, \\ Sharon D. Dell, $M D^{3}$, Stephanie D. Davis, $M D^{I}$, Michael R. Knowles, $M D^{4}$, \\ and Maimoona A. Zariwala, PhD
}

\begin{abstract}
Primary ciliary dyskinesia is a genetically heterogeneous disorder of motile cilia. Most of the disease-causing mutations identified to date involve the heavy (dynein axonemal heavy chain 5) or intermediate (dynein axonemal intermediate chain 1 ) chain dynein genes in ciliary outer dynein arms, although a few mutations have been noted in other genes. Clinical molecular genetic testing for primary ciliary dyskinesia is available for the most common mutations. The respiratory manifestations of primary ciliary dyskinesia (chronic bronchitis leading to bronchiectasis, chronic rhino-sinusitis, and chronic otitis media) reflect impaired mucociliary clearance owing to defective axonemal structure. Ciliary ultrastructural analysis in most patients $(>80 \%)$ reveals defective dynein arms, although defects in other axonemal components have also been observed. Approximately 50\% of patients with primary ciliary dyskinesia have laterality defects (including situs inversus totalis and, less commonly, heterotaxy, and congenital heart disease), reflecting dysfunction of embryological nodal cilia. Male infertility is common and reflects defects in sperm tail axonemes. Most patients with primary ciliary dyskinesia have a history of neonatal respiratory distress, suggesting that motile cilia play a role in fluid clearance during the transition from a fetal to neonatal lung. Ciliopathies involving sensory cilia, including autosomal dominant or recessive polycystic kidney disease, Bardet-Biedl syndrome, and Alstrom syndrome, may have chronic respiratory symptoms and even bronchiectasis suggesting clinical overlap with primary ciliary dyskinesia. Genet Med 2009:11(7):473-487.
\end{abstract}

Key Words: primary ciliary dyskinesia, PCD, Kartagener syndrome, situs inversus, dynein

\section{OVERVIEW}

Primary ciliary dyskinesia (PCD) (MIM no. 244400) is a genetically heterogeneous, typically autosomal recessive, disorder characterized by ciliary dysfunction and impaired mucociliary clearance, resulting in an array of clinical manifestations,

From the ${ }^{1}$ Department of Pediatrics, University of North Carolina School of Medicine, Chapel Hill, North Carolina; ${ }^{2}$ Department of Pediatrics, Washington University School of Medicine, St. Louis, Missouri; ${ }^{3}$ Child Health Evaluative Sciences, Research Institute, The Hospital for Sick Children, Toronto, Ontario, Canada; ${ }^{4}$ Department of Medicine, University of North Carolina School of Medicine, Chapel Hill, North Carolina; and ${ }^{5}$ Department of Pathology and Laboratory Medicine, University of North Carolina School of Medicine, Chapel Hill, North Carolina.

Maimoona A. Zariwala, PhD, FACMG, Department of Pathology and Laboratory Medicine, The University of North Carolina at Chapel Hill, Campus Box 7248, 7123 Thurston-Bowles Bldg, Chapel Hill, NC 27599-7248. E-mail: zariwala@med.unc.edu.

Disclosure: The authors declare no conflict of interest.

Submitted for publication January 30, 2009.

Accepted for publication March 11, 2009.

Published online ahead of print April 25, 2009.

DOI: $10.1097 /$ GIM.0b013e3181a53562 including chronic bronchitis leading to bronchiectasis, chronic rhino-sinusitis, chronic otitis media, situs inversus (in approximately $50 \%$ of cases), and male infertility. The incidence of PCD is estimated at $1 / 16,000$ births based on prevalence of situs inversus and bronchiectasis. ${ }^{1,2}$ However, few patients with PCD carry a well-established diagnosis, which reflects the limited ability to diagnose this disorder.

The first case, reported in the early 1900s, and characterized by a triad of symptoms that included chronic sinusitis, bronchiectasis, and situs inversus, ${ }^{3}$ became known as Kartagener syndrome. Subsequently, patients with Kartagener syndrome, as well as other patients with chronic sinusitis and bronchiectasis, were noted to have "immotile" cilia and defects in the ultrastructural organization of cilia. ${ }^{4-6}$ Initially, the term "immotile cilia syndrome" was used to describe this disorder; however, later studies showed that most cilia were motile, but exhibited a stiff, uncoordinated, and/or ineffective beat. The name was changed to "primary ciliary dyskinesia" to more appropriately describe its heterogeneous genetic base and the ciliary dysfunction, and to distinguish it from the secondary ciliary defects acquired after multiple causes of epithelial injury.

The "gold-standard" diagnostic test for PCD has been electron microscopic ultrastructural analysis of respiratory cilia obtained by nasal scrape or bronchial brush biopsy. Recent studies have identified mutations in several genes encoding structural and/or functional proteins in cilia. Limited clinical genetic testing is currently available, but a multicenter, international collaboration is focused on defining additional PCD-specific gene mutations to expand PCD genetic testing. Recently, nasal nitric oxide (NO) measurement has been used as a screening test for PCD, because nasal NO is extremely low (10-20\% of normal) in patients with PCD. ${ }^{7-10}$ As an adjunct test, nasal NO measurement can identify individuals with probable PCD (even if ciliary ultrastructure appears normal) to target for genetic testing. We anticipate that genetic testing for PCD will soon become the gold standard diagnostic test in a growing number of cases.

In summary, we are in the midst of a revolution for the diagnosis, and understanding of genotype/phenotype correlations in PCD. This effort has greatly benefited from an National Institutes of Health-sponsored Rare Disease Network (http:// rarediseasesnetwork.epi.usf.edu/), and a consortium focused on studying genetic disorders of mucociliary clearance, including PCD (http://rarediseasesnetwork.epi.usf.edu/gdmcc/index.htm).

\section{CILIARY STRUCTURE AND FUNCTION}

\section{Normal ultrastructure of motile cilia}

Cilia and flagella are evolutionarily ancient organelles whose structure and function have been rigidly conserved across the phylogenetic spectrum. Historically recognized for their role in cell motility and transport of fluids over mucosal surfaces, cilia have recently been recognized to have a sensory function that modulates elements of development and cell function. Both 


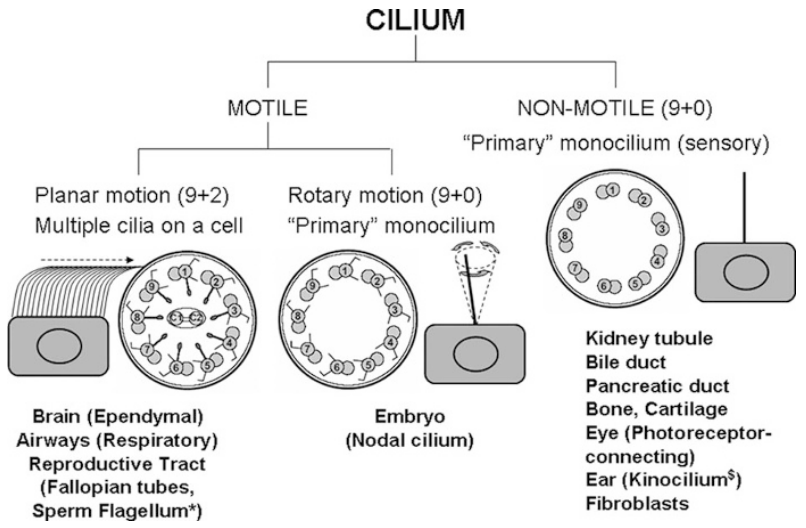

Fig. 1. Diversity of ciliary axoneme. Crosssection of nonmotile ( $9+0$ arrangement) and motile cilia $(9+2$ and 9 +0 arrangement) is shown. 27,182 Studies to date have not determined whether the $9+0$ monocilium has radial spokes. The model showing synchronous motion of motile cilia $(9+2)$, rotatory motion of motile monocilium $(9+$ $0)$, and immotile monocilium $(9+0)$. *Solitary axoneme in the sperm mirrors the structure of the cilium. \$Subcellular structure of the kinocilum is debatable. Some reports indicate $9+0$, whereas others indicate $9+2$ configuration. The function of the kinocilium is also not clear as it disappears during the mammalian early postnatal period. ${ }^{183}$ motile and sensory cilia are composed of highly organized arrays of microtubules and attendant accessory elements and their classification is depicted in Figure 1. Microtubules are formed from $\alpha$ - and $\beta$-monomers of tubulin configured into helical patterns of protofilaments. The peripheral microtubules in the canonical $9+2$ microtubular pattern of motile cilia are studded with dynein arms that contain adenosine triphosphatases and act as molecular motors to effect the sliding of the peripheral microtubular pairs relative to one another. The outer dynein arms (ODA) are positioned proximal to the ciliary membrane and the inner dynein arms (IDA) proximal to the central apparatus of the A microtubule. The dynein arms are large protein complexes each comprised several heavy, light, and intermediate chains as shown in Figure 2. In Chlamydomonas, and likely other eukaryotic cilia and flagella-bearing cells, the IDA and ODA are spaced in specific linear repeats of $96 \mathrm{~nm}$ and $24 \mathrm{~nm}$, respectively, ${ }^{11,12}$ along the axis of each microtubular pair, where they undergo an attachment, retraction, and release cycle with the neighboring microtubular pair that imposes a sliding motility of the pairs relative to one another. The A microtubule in crosssection is comprised of 13 protofilaments and shares three protofilaments with the B microtubule. Studies of isolated axonemes depleted of accessory structures have shown that in the presence of adenosine triphosphate the microtubular pairs slide upon one another to visible light extinction. It is thought that some of the accessory structures, including the nexin links, radial spokes, and ciliary membrane provide shear forces that transition the sliding event to the bending characteristic of ciliary waveform. In contrast to the $9+2$ pattern of motile cilia with dynein motors, there are structural variants without dynein motors that have a $9+0$ microtubular

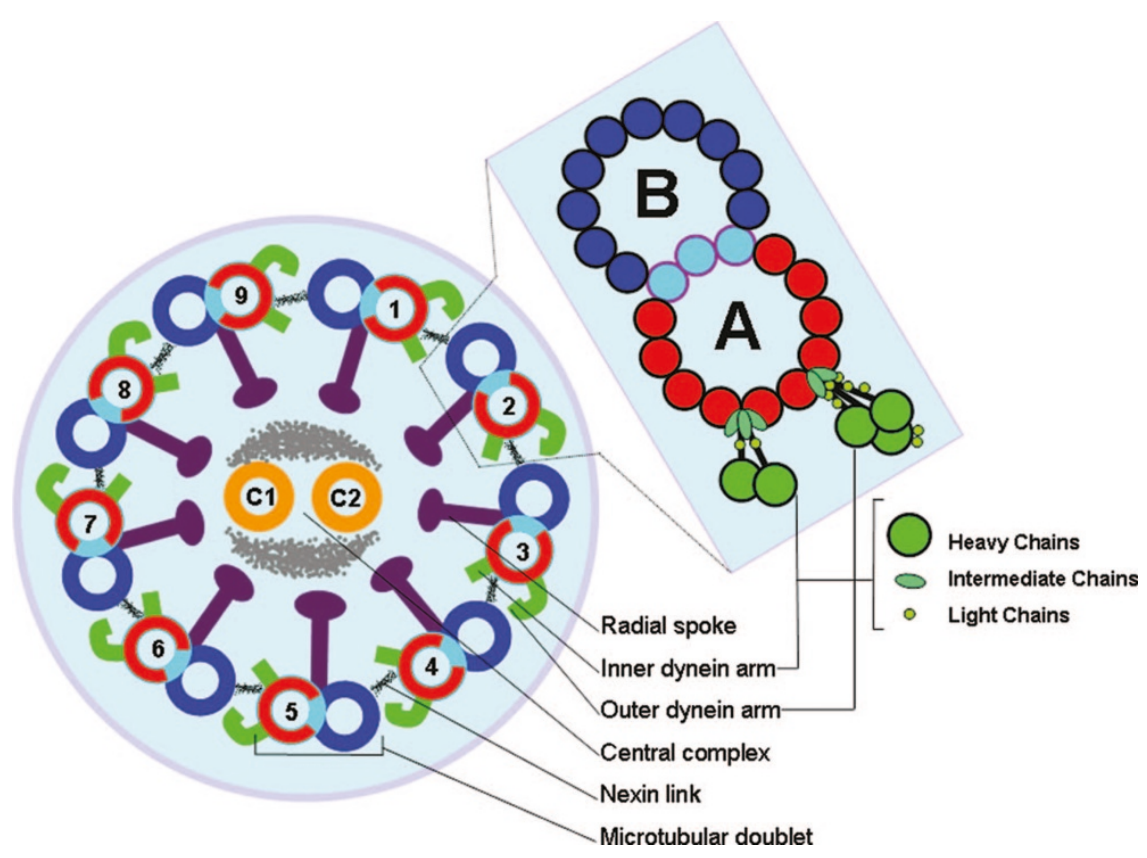

Fig. 2. Schematic diagram of the eukaryotic cilium. Crosssection illustrates the $9+2$ configuration of nine peripheral microtubular doublets surrounding a central pair microtubule complex. The expanded view of a microtubular doublet schematically depicts crosssections of the tubulin protofilaments including those shared by the A and B tubules. The dynein arms in the expanded view are rendered to schematically depict several light, intermediate, and heavy chains comprising each of these structures. Although the outer arm exhibits a specific distribution of dyneins, being uniformly composed of three heavy, two intermediate and at least eight light chains, the distribution of dyneins in the inner arm is thought to be more variable. 
pattern, ${ }^{13}$ which are called "primary" cilia. Unlike the numerous motile cilia present on airway epithelial cells, these primary cilia are borne as solitary appendages. Historically thought to be nonfunctional or vestigial, they have been rediscovered in recent years as structures central to organ positioning during embryologic development and to the detection of mechanical and chemical gradients. Thus, primary cilia are now recognized as structures modulating detection, orientation, and positioning. Virtually, all cells are capable of producing a single primary cilium, which lacks dynein arms and is immotile. However, it has been suggested that populations of both nonmotile primary cilia and specialized motile cilia are present in nodal cells, and that dyneins on the motile populations confer a whirling motility to the organelle that is distinct from the waveform motility typical of $9+2$ motile cilia. Thus, there are three basic groups of cilia; motile $9+2$ cilia with attendant dynein arm structures (e.g., respiratory epithelial cells), nonmotile $9+0$ primary cilia lacking dynein arms (e.g., kidney tubules), and motile $9+0$ primary cilia possessing dynein arms (e.g., embryonic node). In addition to the highly specialized organization of the core of the cilium, the ciliary membrane exhibits a specialized structure, the ciliary necklace at the base of the axonemal shaft. ${ }^{14}$ The ciliary necklace has been speculated to be a docking/assembly site for axonemal elements, because nascent organizing structures of these arrays have been reported on the luminal membranes of cells in early stages of ciliogenesis. ${ }^{15}$

\section{Normal ciliary beat frequency}

Two distinctive types of motility are representative of $9+2$ and $9+0$ motile cilia. Ciliated epithelial cells bear approximately 200 motile $(9+2)$ cilia that move with both intracellular and intercellular synchrony. The pattern of beat in $9+2$ motile cilia occurs in a waveform having a forward effective stroke followed by a return stroke. The direction of stroke is a function of the directional orientation of the central microtubules. In addition to moving in synchrony, individual cilia in normal cells are very plastic and move fluidly, sometimes deforming briefly upon encountering resistance and/or particles being transported over the mucosal surface. Cilia are embedded in a watery periciliary fluid of low viscosity, which facilitates the rapid beat cycle to move the more viscous overlying layer of mucus. Ciliary beat frequency ranges from approximately $8-20 \mathrm{~Hz}$ under normal conditions but may be accelerated by exposure to irritants such as tobacco smoke. ${ }^{16}$ The mechanism whereby beat frequency is accelerated has been suggested to be regulated through the activity of NO synthases localized in the apical cytoplasm. Although baseline ciliary beat frequency is not thought to be under NO regulation, NO accelerates ciliary beat frequency in response to challenge through soluble adenylyl or guanylyl cyclase to form their respective cyclic nucleotides with activation of protein kinase $\mathrm{G}$ (PKG) and A (PKA) to accelerate beat frequency. ${ }^{17,18}$ Increases in intracellular calcium fluxes ${ }^{19,20}$ may also play a role in accelerating ciliary beat frequency.

In contrast to the forward/return waveform of $9+2$ cilia, motile nodal $9+0$ cilia beat with a vertical motion. This type of motility is thought to direct nodal flow "leftward" across the node, which is necessary for establishment of proper left/right asymmetry.

\section{Cilia composition and conservation across species}

The ciliary genome is highly conserved across the phylogenetic spectrum from simple unicellular eukaryotes and lower animals to functionally complex mammalian cells and tissues. The genomes for many organisms are already characterized and the simple organisms are easily grown in substantive quantities and manipulated in the laboratory setting to facilitate structural, functional, and genetic studies. This provides opportunities to identify cilia-specific mutations that may represent candidate genes for human ciliopathies. ${ }^{21}$ Indeed, mutations conferring ODA defects in PCD have orthologs in Chlamydomonas. ${ }^{22}$ Moreover, genes encoding polycystins and intraflagellar transport proteins in Chlamydomonas also have orthologs with relevance to polycystic kidney disease. ${ }^{23,24}$ Hence, studying orthologous genes across the various species is valuable to decipher the candidate genes for human ciliopathies.

\section{GENETICS}

\section{Genetic heterogeneity: Challenges and methods to identify disease-causing genes}

Dysfunction of the axonemal structure has been linked to the emerging class of disorders collectively known as "ciliopathies," which includes PCD/Kartagener syndrome, Bardet-Biedl syndrome, hydrocephalus, polycystic kidney disease, polycystic liver disease, nephronophthisis, Meckel-Gruber syndrome, Joubert syndrome, Alstrom syndrome, Jeune syndrome, and laterality defects. ${ }^{25-28} \mathrm{PCD}$ was the first human disorder linked to the dysfunction of motile cilia and that will be discussed in detail in this chapter.

Axonemal structure, which is conserved through evolution, is complex and comprised of multiple proteins; hence, it is not surprising that PCD is a genetically heterogeneous disorder posing challenges for defining causative genes. Conventional family-based genome wide linkage studies have failed to identify PCD causing genes, ${ }^{29}$ because combining data from multiple families limits power when dealing with a genetically heterogeneous disorder, such as PCD. Multiple other methodologies alone, or in combination, have been successfully applied to elucidate the genetic basis of PCD, including functional candidate gene testing, ${ }^{30-34}$ homozygosity mapping ${ }^{35-37}$ followed by positional candidate gene analysis, and comparative computational analysis involving comparative genomics, transcriptomics, and proteomics. ${ }^{38-43}$ Thus far, mutations have been identified in eight genes (Table 1) in PCD (DNAI1, DNAH5, DNAH11, DNAI2, KTU, RSPH9, RSPH4A, and TXNDC3) but no genotype/phenotype associations have been defined and these genes are discussed in detail later.

\section{Dynein axonemal intermediate chain 1}

Dynein axonemal intermediate chain 1 (DNAI1) (MIM no. 604366), was the first PCD-causing gene to be identified based on the candidate gene approach. This approach takes advantage of the fact that the axoneme is highly conserved through evolution, and human orthologs of the genes known to cause specific ultrastructural and functional defect in other species are candidates for PCD. Chlamydomonas is a biflagellate, unicellular algae with well studied genetics and multiple motility mutants. One such mutant (oda9) had a mutation in the IC78 (intermediate chain 78) gene, resulting in a flagellar ODA defect. The human ortholog of IC78 (DNAI1) was cloned and tested in six unrelated patients with PCD with ODA defects and biallelic mutations were identified in one patients with PCD. ${ }^{33}$ Two studies reported biallelic mutations in three additional unrelated patients with PCD. ${ }^{44,45}$ Subsequently, a large study comprised of 179 unrelated patients revealed 9\% (14 with biallelic and two with only monoallelic mutations) of all patients with PCD carry mutations in DNAII. ${ }^{46}$ Thus, taken together from all published literature, mutations in DNAII were seen in approximately $10 \%$ (22 of 226) of all patients with PCD 
Table 1. Candidate genes tested and found to be mutated in PCD patients

\begin{tabular}{|c|c|c|c|c|c|}
\hline Human gene & Axonemal component & $\begin{array}{c}\text { No. PCD } \\
\text { families tested }\end{array}$ & $\begin{array}{c}\text { No. PCD families } \\
\text { with biallelic mutations }\end{array}$ & $\begin{array}{c}\text { No. PCD families } \\
\text { with only monoallelic mutations }\end{array}$ & References \\
\hline DNAH5 & ODA HC & 134 & 28 & 10 & $36,50,51$ \\
\hline DNAH11 & ODA HC & 2 & 2 & 0 & 30,37 \\
\hline \multirow[t]{2}{*}{ DNAII } & ODA IC & 226 & 20 & 2 & $33,44-46$ \\
\hline & & 104 & 2 & 2 & 48 \\
\hline \multirow[t]{3}{*}{$D N A I 2$} & ODA IC & 10 & 0 & 0 & 34 \\
\hline & & 6 & 0 & 0 & 53 \\
\hline & & 106 & 3 & 0 & 35 \\
\hline$T X N D C 3$ & ODA LC/IC & 41 & 1 & 0 & 31 \\
\hline$K T U$ & Cytoplasmic $^{a}$ & 112 & 2 & 0 & 32 \\
\hline RSPH9 & RS & 2 & 2 & 0 & 56 \\
\hline RSPH4A & $\mathrm{RS}$ & 5 & 5 & 0 & 56 \\
\hline
\end{tabular}

${ }^{a}$ Cytoplasmic protein requires for the dynein arms assembly.

ODA, outer dynein arm; IDA, inner dynein arm; HC, heavy chain; IC, intermediate chain; LC, light chain; RS, radial spoke.

and it increased to $14 \%$, if only patients with ODA defects were considered. ${ }^{33,44-46}$ Despite allelic heterogeneity, the IVS1+2_3insT founder mutation represented $55 \%$ of all the mutant alleles, as well as mutation clusters were seen in other exons (exons 13, 16, and 17), and these observations became the basis for the clinical molecular genetic test for PCD. ${ }^{33,44-47}$ In addition, IVS1+2_3insT founder mutation seems to be more common in individuals of the white descent. ${ }^{46}$ A recent study from Europe in 104 patients with PCD (without phenotypic preselection) revealed biallelic mutations in DNAI1 in only $2 \%$ of the patients. ${ }^{48}$ Interestingly, these authors also observed three unrelated patients with PCD harboring the IVS1+2_3insT founder mutation in DNAII.

\section{Dynein axonemal heavy chain 5}

The DNAH5 (MIM no. 603335) gene was identified as a causative gene for PCD using homozygosity mapping. This approach requires the analysis of a large affected inbred family and assumes that the recessive disorder is caused by a homozygous mutation that is inherited from the common ancestor. Using a large Arab inbred family with PCD, Omran et al. ${ }^{49}$ found the locus on Chromosome 5, which included DNAH5 within the shared interval. DNAH5 was a candidate gene for PCD because the mutation in its ortholog $\gamma$-HC (gamma-heavy chain) in Chlamydomonas caused flagellar immotility and ODA defects; and indeed, mutations were observed in eight unrelated PCD families. ${ }^{36}$ Subsequently, the same group carried out large scale studies using 134 unrelated patients with PCD and found that $\sim 28 \%$ of all patients with PCD harbor mutations in DNAH5.50,51 Despite allelic heterogeneity, mutation clusters were observed in five exons (exons 34, 50, 63, 76, and 77), which assisted in the development of the first clinical molecular genetic test for PCD. ${ }^{47}$ Immunofluorescence studies on the respiratory epithelium and sperm flagella of patients known to harbor biallelic DNAH5 mutations showed that the mutant protein is present in the microtubule organizing center of the respiratory epithelial cells but failed to localize along the axonemal shaft. ${ }^{28,52}$ Interestingly, sperm analysis from a male patient showed normal immunofluoresence staining pattern; thus, DNAH5 is not mislocalized in the sperm flagella. ${ }^{52}$

\section{Dynein axonemal intermediate chain 2}

The dynein axonemal intermediate chain 2 (DNAI2) (MIM no. 605483) is an intermediate chain dynein of the ODA that was cloned and characterized using the candidate gene approach. Mutations in the Chlamydomonas ortholog (IC69) caused an immotile mutant strain (oda6), which had loss of ODA. ${ }^{34}$ Initial studies showed no disease causing mutations in 16 PCD families, including six families with microsatellite marker alleles concordant for loci on chromosome 17q23-ter (locus for DNAI2). ${ }^{34,53}$ Very recently, Loges et al. ${ }^{35}$ used homozygosity mapping and identified linkage to the DNAI2 locus in a consanguineous Iranian Jewish family, and a homozygous splice mutation (IVS11+1G $>$ C) in all the affected individuals. Subsequently, they sequenced an additional 105 unrelated patients (48 with ODA defects) and identified a homozygous splice mutation (IVS3-3T $>$ G) in a Hungarian PCD family and a homozygous stop mutation (R263X) in a German patient. Thus, DNAI2 mutations are found in $\sim 2 \%$ of all PCD families and $4 \%$ of PCD families with documented ODA defects. ${ }^{35}$

\section{Dynein axonemal heavy chain 11}

Genetics of DNAH11 (MIM no. 603339) are still emerging. A patient with uniparental isodisomy of Chromosome 7 presented with cystic fibrosis (CF) due to the common homozygous mutation (deltaF508) in CFTR (MIM no. 602421). In addition, this patient had situs inversus, which is not part of the spectrum of CF. ${ }^{30}$ Upon investigation of the region near CFTR on Chromosome 7, DNAH11 emerged as a candidate gene because mutations in the ortholog $\beta$-HC (beta-heavy chain) dynein and left right dynein (lrd) caused motility defects in Chlamydomonas oda4 mutant strain (reviewed in Ref. 22) and situs inversus in mice ${ }^{54,55}$ respectively. Sequencing of DNAH11 in this CF patient with situs inversus revealed a homozygous nonsense mutation (R2852X). ${ }^{30}$ Because this patient had airways disease due to $\mathrm{CF}$ and no defined ciliary ultrastructural defect, it was not 
certain whether the patient also had PCD, or only isolated situs inversus; hence, the status of DNAH11 as a PCD causing gene remained undefined. Very recently, a large German family with five affected individuals (and Kartagener syndrome) was found to harbor biallelic compound heterozygous truncating mutations in DNAH11.37 Although, the electron microscopic analysis and immunofluorescence localization in these patients showed normal dynein arms, they had abnormal ciliary beat patterns. Because patients with PCD with normal dynein arms are difficult to diagnose, it will be important to carry out large-scale genetic studies of DNAH11 in PCD subjects to decipher whether DNAH11 plays an important role in patients with PCD with normal DA.

\section{Thioredoxin-nucleoside diphosphate}

Thioredoxin-nucleoside diphosphate (TXNDC3) (MIM no. 607421) ortholog in Chlamydomonas (light chain 3 and light chain 5) and sea urchin (intermediate chain 1) is a component of sperm ODA. Because of the involvement of TXNDC3 in the ODA, it was considered a candidate gene and tested in 41 unrelated patients with PCD. ${ }^{31}$ Only one patient harbored a nonsense mutation (L426X) on one allele inherited from the mother ${ }^{31}$ and a common intronic variant (c.271-27C $>$ T) on the trans allele. Although this variant is present in $1 \%$ of non-PCD control subjects, it occurs near the branch point in the intron that is involved in the splicing. TXNDC3 encodes two transcripts, one full length isoform and a novel short isoform TXNDC3 $\mathrm{d} 7$ (inframe deletion of exon 7) that is thought to bind microtubules. The authors concluded that the variant was pathogenic in the patient with a nonsense mutation on one allele and the variant on the other allele because the levels of the short isoform (TXNDC3d7) were reduced in this patient with PCD thereby affecting the ratio of the two isoforms. ${ }^{31}$

\section{KTU}

A truncating homozygous mutation in Ktu (previously known as Kintoun or knt) (MIM no. 612517) in Medaka fish causes laterality defects, polycystic kidney disease, and impaired sperm motility in male fish. Ultrastructural analysis of the cilia of Kupffer vesicle (functionally equivalent to the mouse node) and flagella of sperm from the fish revealed ODA + IDA defects. ${ }^{32}$ Similar ultrastructural defects were found in the paralyzed flagella mutant strain of Chlamydomonas ( $p f 13)$ that harbored mutation in the $P F 13$ gene (ortholog of $K T U$ ), required for the ODA assembly. ${ }^{32} K T U$ does not belong to the dynein family genes, but it is a cytoplasmic protein that is required for the assembly of the dynein complex and hence was considered a candidate gene for PCD. ${ }^{32}$ A total of 112 unrelated patients with PCD were tested for the mutations in $K T U$ and two unrelated inbred families were found to harbor truncating mutations; the ciliary ultrastructural analysis revealed ODA + IDA defects. Of the 112 PCD families tested, only 17 had defined ODA + IDA defects; thus, mutations in KTU occur in $12 \%$ patients with PCD with ODA + IDA defects. ${ }^{32}$ Interestingly, $K T U$ mutations caused PCD in humans, but polycystic kidney disease in fish, perhaps due to the difference in the origin of the kidneys that are mesonephric in fish and metanephric in mammals.

\section{Radial spoke head protein 9}

Very recently, Castleman et al. ${ }^{56}$ identified the mutations in radial spoke head protein 9 (RSPH9). The authors carried out homozygosity mapping and identified the disease interval on Chromosome 6 and subsequently discovered the inframe deletion (K268del) in RSPH9 in two Arab Bedouin families. The ultrastructural analysis from the patients who harbored mutations was the mixture of $9+2$ or $9+0$ microtubular configuration in one family and the normal dynein arms in the other family. ${ }^{56}$ Interestingly, Chlamydomonas motility-defective mutant, $p f 17$ that harbors mutation in the orthologous gene RSP9, shows the absence of entire radial spoke head and the central pair displacement. ${ }^{57}$

\section{Radial spoke head protein $4 A$}

Another PCD causing gene that has emerged very recently is radial spoke head protein 4A $(R S P H 4 A) .{ }^{56}$ This gene was identified by the virtue of homozygosity mapping in three inbred Pakistani families. Homozygous nonsense mutation (Q154X) was identified in all three inbred and one out-bred Pakistani families in RSPH4A. In addition, one family of a white descent was compound heterozygous for the mutations (Q109X + $\mathrm{R} 490 \mathrm{X}$ ) in this gene. Ultrastructural analysis in all of the five PCD families with the mutation showed transposition defects with the absence of central pair and $9+0$ or $8+1$ microtubule configurations. ${ }^{56} \mathrm{RSPH} 4 \mathrm{~A}$ is orthologous to the Chlamydomonas RSP4 and RSP6. However, Chlamydomonas motility-defective mutants $p f 1$ and $p f 26$ lacking $R S P 4$ or $R S P 6$, respectively, show absence of radial spoke head. ${ }^{58}$

\section{Genes tested and found to be negative in PCD}

A number of other PCD candidate genes have been tested and found to be negative in PCD patients. These genes include DNAH9 (dynein axonemal heavy chain 9), DNAH17 (dynein axonemal heavy chain 17), DNAL1 (dynein axonemal light chain 1), DNAL4 (dynein axonemal light chain 4), TCTE3 (T complex-associated testis-expressed 3), DYNLL2 (dynein light chain 2), DNALI1 (dynein axonemal light intermediate polypeptide 1 [HP28]), DNAH3 (dynein axonemal heavy chain 3), DNAH7 (dynein axonemal heavy chain 7), SPAG6 (spermassociated antigen 6), SPAG16 (sperm-associated antigen 16), $D P C D$ (deleted in PCD), and FOXJ1 (forkhead box J1 [HFH-4]). The details about the number of patients tested for each of these genes is given in Table 2. Some of these genes may still be candidates for PCD as they were either tested in a small cohort of patients or the patients were not preselected based on ultrastructural findings to test for the appropriate axonemal component gene.

\section{PCD cosegregating with other syndromes (OFD1 and $R P G R$ )}

In a few instances, PCD cosegregates with other genetic conditions and the causative genes primarily do not affect ciliary motor function. A large inbred Polish kindred was identified with a novel X-linked mental retardation syndrome, together with the compatible clinical PCD phenotype and dyskinetic cilia. Linkage studies followed by comparative genomic analysis identified the locus on the $\mathrm{X}$ chromosome including OFD1 (formerly known as CXORF5) (MIM no. 311200). Mutation analysis confirmed the frameshift mutation in $O F D 1$ in all the affected individuals tested from the Polish family. ${ }^{59}$ OFD1 is localized to the centrosomes and the basal body of the primary cilia and does not affect ciliary motor function. ${ }^{60,61}$ The index patient with the $O F D 1$ mutation had disorganized ciliary beat suggesting the role of OFD1 in the respiratory epithelial ciliary function. ${ }^{59}$

A family consisting of two probands has been described by Moore et al., ${ }^{62}$ with the X-linked retinitis pigmentosa (xlRP) (MIM no. 268000), oto-sino-pulmonary symptoms consistent with PCD, and multiple abnormalities of all the ciliary components by ultrastructural analysis. Upon sequencing, both patients harbored a $57 \mathrm{bp}$ deletion that is predicted to cause a truncated protein in $R P G R$ that resides on the $\mathrm{X}$ chromosome (MIM no. 312610). ${ }^{62}$ Furthermore, Zito et al., ${ }^{63}$ described a patient with PCD and mild hearing loss together with xlRP. 
Table 2. Candidate genes were tested and found to be negative in PCD patients

\begin{tabular}{|c|c|c|c|c|c|}
\hline Human gene & Axonemal component & $\begin{array}{c}\text { No. PCD } \\
\text { families tested }\end{array}$ & $\begin{array}{l}\text { No. PCD families } \\
\text { with biallelic mutations }\end{array}$ & $\begin{array}{c}\text { No. PCD families } \\
\text { with only monoallelic mutations }\end{array}$ & References \\
\hline DNAH9 & ODA HC & 2 & 0 & 0 & 184 \\
\hline DNAH17 & ODA HC & 4 & 0 & 0 & 185 \\
\hline DNAL1 & ODA LC & 86 & 0 & 0 & 186 \\
\hline DNAL4 & ODA LC & 54 & 0 & 0 & 187 \\
\hline TCTE3 & ODA LC & 36 & 0 & 0 & 188 \\
\hline DYNLL2 & ODA LC & 58 & 0 & 0 & 53 \\
\hline DNALI1 (HP28) & IDA LC & 61 & 0 & 0 & 187,189 \\
\hline$D N A H 3$ & IDA HC & 7 & 0 & 0 & 190 \\
\hline DNAH7 & IDA HC & 1 & 0 & 0 & 191 \\
\hline$D P C D$ & IDA gene & 51 & 0 & 0 & 96 \\
\hline SPAG6 & $\mathrm{CA}$ & 54 & 0 & 0 & 185 \\
\hline$S P A G 16$ & CA & 5 & 0 & 0 & 192 \\
\hline FOXJI/HFH-4 & Expressed $^{a}$ & 8 & 0 & 0 & 89 \\
\hline
\end{tabular}

${ }^{a}$ Expressed in respiratory cilia.

ODA, outer dynein arm; IDA, inner dynein arm; HC, heavy chain; IC, intermediate chain; LC, light chain; CA, central apparatus.

They detected a frameshift mutation in $R P G R$. In addition, Iannaccone et al. ${ }^{64}$ reported a family with PCD and otitis media with bronchitis together with xlRP and the presence of a missense mutation in RPGR. RPGR protein is expressed in rods and cones and is essential for photoreceptor maintenance and viability. ${ }^{65}$ RPGR is also expressed in cochlear, bronchial, and sinus epithelial lining cells, ${ }^{64,66}$ indicating a possible functional role for the broad phenotype in patients with $R P G R$ mutations.

\section{Animal models for PCD}

Animal models for PCD are available that are either naturally occurring or constructed via genetic manipulations. They include dogs, ${ }^{67-71}$ cats, ${ }^{72}$ pigs, ${ }^{73}$ rats, ${ }^{74}$ and mice. Causative genes in the animal models other than the mouse models are not yet known. Several axonemal component gene knock-out mice have been created including Mdnah5 (mouse dnah5), ${ }^{75,76}$ lrd, ${ }^{54,55,77-79} \mathrm{Dpcd} /$ poll (deleted in PCD/polymerase lambda), ${ }^{80}$ Pcdpl (PCD protein 1), ${ }^{81}$ hydin, ${ }^{82-85}$ Tektin-t,${ }^{86}$ Mdhc7 (mouse dynein heavy chain 7, human ortholog [DNAH1]), ${ }^{87,88}$ Foxj1/ Hfh4, ${ }^{89}$ Spag16,90-92 Spag6,90,93 and Spag16/Spag6 double knock-outs. ${ }^{94}$ None of these mice models presented with the classic PCD phenotype, except for the Mdnah5 and Dpcd/poll. None of these genes harbored mutations in the human orthologs (Tables 1 and 2) in the patients with PCD, except for the Mdnah5 and lrd (discussed in detail later).

\section{Mdnah5 deficient mouse}

Mdnah5 nullizygous mice were generated by transgenic insertional mutagenesis that led to a frameshift mutation. These mice presented with the classical features of PCD, including respiratory infections, situs abnormalities, immotility of the cilia, and ultrastructural analysis revealing absent ODA. ${ }^{75}$ Consistent with the autosomal recessive mode of inheritance, only homozygous mutant mice presented with the PCD phenotype. Almost all homozygous mutant mice developed hydrocephalus leading to perinatal lethality and indeed partial ODA defects were noted in the ependymal cells that are lining the brain ventricles and the aqueduct. ${ }^{95}$ Recently, another group identified the homozygous mice with an inframe deletion of 593 amino acids (exons 7-17) during the ENU (ethylnitrosourea) mutagenesis screen. ${ }^{76}$ These mice (known as Dnahc5 $\mathrm{del}^{593}$ ) presented with dyskinetic cilia and ODA defects in respiratory cilia. Mice presented with situs inversus totalis $(35 \%)$ and heterotaxy $(40 \%)$ with congenital heart defects leading to postnatal lethality. DNAH5 is the only gene thus far known to cause PCD in humans and mice. ${ }^{36,51}$

\section{Other interesting mouse models}

Another mouse model with the classic PCD phenotype is Dpcd/poll knock-out mice presenting with sinusitis, situs inversus, hydrocephalus, male infertility, and ciliary IDA defect. ${ }^{80}$ The initial study considered the mouse phenotype to be caused by the homozygous deletion of poll, 80 but later it was discovered that another gene known as Dpcd was also deleted in these mice. ${ }^{96}$ In addition, mice generated with the catalytic domain of poll did not have a PCD phenotype. ${ }^{97}$ Thus, taken together, it seems that poll is not a candidate for the PCD phenotype in these mice that may be due to the $D p c d$ deletion. The human ortholog $(D P C D)$ was tested in 51 patients with PCD (15 with IDA defects) and no mutations were discovered. ${ }^{96}$ A noteworthy model is for the left-right dynein (lrd) deficient mice (lrd mice, $I V$ mice, and $l g l$ mice), where classic PCD phenotype is not observed, but these mice present with the situs abnormalities and normal dynein arms by ultrastructural analysis. ${ }^{54,55,77-79}$ Interestingly, mutations have been observed in the human ortholog of lrd (DNAH11) in patients with PCD. ${ }^{30,37}$

\section{CLINICAL FEATURES}

\section{Introduction}

Ciliated cells line the airways of the nasopharynx, middle ear, paranasal sinuses, and lower respiratory tract from the trachea to 
the terminal airways. ${ }^{98}$ Each ciliated cell has approximately 200 cilia projecting from its surface in the same orientation. Coordinated movement of the cilia sweeps the periciliary fluid and overlying mucus, resulting in vectoral movement of mucus out of the lower respiratory tract. The mucociliary escalator is the primary defense mechanism of the airways, ${ }^{99,100}$ and any functional disruption, primary or acquired, can lead to chronic sino-pulmonary symptoms.

\section{Early clinical manifestations}

The clinical features of PCD manifest early in life (Table 3). Most patients with PCD $(70-80 \%)$ present in the neonatal period with respiratory distress, which suggests that motile cilia are critical for effective clearance of fetal lung fluid. ${ }^{9,101-103}$ Several case reports have emphasized unexplained atelectasis or pneumonia in term newborns, which can present with hypoxemia or even acute respiratory failure requiring mechanical ventilation. Despite this early clinical feature, the association of newborn respiratory distress with PCD has been underrecognized and diagnosis is often delayed. In a retrospective review, investigators have found the mean age of PCD diagnosis was more than 4 years of age despite these early pulmonary manifestations. ${ }^{104}$ Persistent rhinitis and chronic cough are present since early infancy. Chronic cough is consistently reported in the majority of subjects (84-100\%), and typically characterized as wet and productive. , $^{105,106}$ The infant may also exhibit poor feeding and failure to thrive in the early years of life, ${ }^{107}$ similar to $\mathrm{CF}$, thus making the diagnosis a challenge.

\section{Table 3. Clinical features of PCD}

\section{Middle ear}

Chronic otitis media

Conductive hearing loss

Nose and paranasal sinuses

Neonatal rhinitis

Chronic nasal congestion and mucopurlent rhinitis

Chronic pansinusitis

Nasal polyposis

Lung

Neonatal respiratory distress

Chronic cough

Recurrent pneumonia

Bronchiectasis

Genitourinary tract

Male (and possibly female infertility)

Laterality defects

Situs inversus totalis

Heterotaxy ( \pm congenital cardiovascular abnormalities)

Central nervous system

Hydrocephalus

Eye

Retinitis pigmentosa

\section{Laterality defects}

A classic phenotypic feature of PCD that may be detected at birth are left-right laterality defects. The prevalence of situs inversus totalis tends to be over $60 \%$ in the pediatric population, as opposed to $50 \%$ in the adult population, suggesting that situs abnormalities may serve as a marker to aid in disease diagnosis. $9,105,106,108,109$ Without functional nodal cilia in the embryonic period, thoracoabdominal orientation is random and not genetically preprogrammed.

\section{Heterotaxy and congenital cardiovascular defects}

Patients with Kartagener syndrome have a greater incidence of congenital cardiovascular defects, and recent studies have found that approximately $6 \%$ of patients with PCD have heterotaxy (situs ambiguus or organ laterality defects other than situs inversus totalis), ${ }^{110}$ which is associated with increased morbidity due to complex cardiovascular anomalies. Heterotaxia syndromes include abdominal situs inversus, polysplenia (left isomerism), and asplenia (right isomerism and Ivemark) syndromes. ${ }^{111}$ It is therefore recommended that patients with anomalies consistent with situs ambiguus or heterotaxy, including congenital heart disease, with neonatal respiratory distress or chronic respiratory tract infections be referred for PCD screening.

\section{Upper respiratory tract}

The upper respiratory tract is frequently involved in PCD. Rhinosinusitis (100\%) and otitis media $(95 \%)$ are cardinal features of the disease and are responsible for much of the morbidity associated with PCD in early childhood. ${ }^{9,104}$ Nasal congestion and/or rhinorrhea are very common, and some patients have nasal polyposis. Middle ear disease is described in virtually all cases of PCD with varying degrees of chronic otitis media and persistent middle ear effusions, such that patients are often first referred to an otolaryngologist, who must have a high index of suspicion for the disease. The middle ear disease often leads to multiple sets of pressure-equalization tubes in early childhood, $9,105,112$ which can be complicated by persistent, purulent otorrhea. Middle ear disease often leads to conductive hearing loss.

\section{Lower respiratory tract}

Most patients (and their family members) report a chronic, productive cough as a prominent symptom of PCD, because cough compensates for the lack of effective mucociliary clearance. Physiologic data have shown that "effective" coughs can produce effective lung clearance, almost equal to normal mucociliary clearance over short-time periods, even in PCD subjects with severe ciliary defects. ${ }^{113}$ Impaired mucociliary clearance of the lower respiratory tract leads to recurrent episodes of pneumonia or bronchitis. Bacterial cultures of lower respiratory secretions most commonly yield nontypeable Haemophilus influenzae, Staphylococcus aureus, and Streptococcus pneumoniae. Pseudomonas aeruginosa infection, including mucoid strains, has also been reported, most often in older individuals. ${ }^{9}$

\section{Bronchiectasis: Severity of disease}

Clinical and radiographic evidence of bronchiectasis develops as the disease progresses, often accompanied by digital clubbing. Review of high-resolution computerized tomography (CT) findings of the lungs showed that bronchiectasis primarily involves the middle and lower lobes $(100 \%$ adults and $55 \%$ pediatric patients). ${ }^{14,115}$ Bronchiectasis and obstructive impairment may be apparent in preschool children. ${ }^{106,116}$ When com- 
pared with $\mathrm{CF}$, pulmonary involvement is generally milder in PCD when controlled for age and gender. Studies examining lung function decline suggest that forced expiratory volume in 1 second $\left(\mathrm{FEV}_{1}\right)$ in a crosssection of patients with $\mathrm{PCD}$ decreases slower than that seen in CF. ${ }^{9,117}$ Patients with PCD can develop chronic respiratory impairment $(25 \%$ in one series) as defined by hypoxemia or an $\mathrm{FEV}_{1}<40 \%$ predicted for age and some may eventually require lung transplantation. 9,118 Pulmonary involvement also adversely impacts quality of life as patients with PCD mature and is increasingly recognized as both medical and public understanding of ciliopathies increases. ${ }^{119}$

\section{Infertility}

Men with PCD are typically infertile as a result of impaired spermatozoa motility secondary to defective sperm flagella, although it is not a universal finding. ${ }^{120,121}$ Men with PCD may occasionally have intact spermatozoa motility, suggesting sperm tails may retain some function or could have different genetic control than cilia. ${ }^{120}$ Female fertility is more variable; with reduced fertility in some that report delay in conception after unprotected intercourse, presumably due to abnormal ciliary function in the Fallopian tube. ${ }^{120,122}$

\section{Other clinical manifestations}

Other clinical manifestations of PCD are rare and less well understood. Several reports have linked hydrocephalus with PCD, hypothetically due to impaired cerebrospinal fluid flow secondary to dysfunctional motile cilia that line the ventricular ependymal cells. ${ }^{123,124}$ Hydrocephalus is frequently found in murine PCD models, but its incidence or clinical relevance in patients with PCD is unclear. Retinitis pigmentosa has recently been linked to some forms of PCD, ${ }^{62-64,125}$ and recently, bronchiectasis was reported in $37 \%$ of patients who have autosomaldominant polycystic kidney disease. ${ }^{126}$ Findings in these studies suggest phenotypic overlap between sensory and motile ciliopathies.

\section{DIFFERENTIAL DIAGNOSIS}

The diagnosis of PCD is often delayed until late childhood or adulthood as a consequence of the heterogeneous nature of the disease, lack of physician knowledge of disease characteristics, and the technical expertise required for an accurate diagnosis. ${ }^{9,104}$ Several clinical presentations warrant consideration of PCD in the differential diagnosis, including infants with unexplained respiratory distress and/or laterality defect, and infants and children who present with chronic cough, nasal drainage and sino-pulmonary disease.

\section{Neonatal respiratory distress}

The differential diagnosis for neonatal respiratory distress in a term infant is extensive, and includes transient tachypnea of the newborn, neonatal pneumonia, and meconium aspiration, ${ }^{127}$ as well as rarer causes such as surfactant protein deficiency ${ }^{128}$ and interstitial lung disease (ILD). Infants with PCD are often misdiagnosed with transient tachypnea of the newborn or neonatal pneumonia in the newborn period. Surfactant protein deficiency, a rare form of ILD (see later), presents in infancy with severe tachypnea and hypoxia, often requiring mechanical ventilation. These children typically have diffuse interstitial disease on chest CT and alveolar proteinosis on bronchoalveolar lavage, neither of which are seen in PCD. ${ }^{129,130}$

\section{Laterality defects}

Situs inversus totalis occurs in approximately $50 \%$ of patients with $\mathrm{PCD}^{9,131}$; approximately $25 \%$ of subjects with situs inversus have PCD. ${ }^{132}$ Other situs anomalies (heterotaxy), such as abdominal situs inversus, polysplenia, and right and left isomerism, may also be found in $\mathrm{PCD}^{110,133}$ and, in conjunction with neonatal respiratory distress, should prompt an evaluation for PCD. Congenital heart disease, especially involving defects of laterality, may also be present in subjects with PCD ${ }^{110,131,133 \text {; }}$ however, respiratory distress secondary to PCD may be difficult to distinguish from distress secondary to cardiac defects, thereby, delaying diagnosis.

\section{Chronic cough, nasal congestion, and sinopulmonary disease}

The differential diagnosis includes $\mathrm{CF}$, asthma, allergic rhinitis, gastroesophageal reflux disease (with or without aspiration), immunodeficiency, ILD, and idiopathic bronchiectasis (Table 4). $9,131,134$

\section{Cystic fibrosis}

Both PCD and CF are characterized by chronic, productive cough, obstructive impairment on lung function testing, ${ }^{116,135-137}$ and radiologic changes including hyperinflation, subsegmental atelectasis, and bronchiectasis. ${ }^{9,134,135,138}$ Parents of PCD children often note that cough was present from birth, which may distinguish these patients from those with CF. ${ }^{9,134}$ Digital clubbing, chronic sinusitis, and nasal polyps can occur in both diseases. ${ }^{9,131,134}$ The gastrointestinal and nutritional issues commonly seen in CF (e.g., failure to thrive, steatorrhea, and liver disease) are not typical of PCD. ${ }^{134,138}$ In contrast, chronic otitis media is a hallmark of PCD, occurring in $90-100 \%$ of patients with PCD, whereas the incidence of otitis media in CF is not increased compared with the general population. ${ }^{9,131} \mathrm{CF}$ can be ruled out by pilocarpine sweat electrolyte testing and/or by CFTR gene mutation analysis. ${ }^{139}$

\section{Asthma and allergic rhinitis}

PCD and asthma can both be characterized by chronic cough; however, this cough is usually dry and nonproductive in asthma as opposed to the wet cough of PCD. ${ }^{140-142}$ Atelectasis is a common finding in both PCD and asthma, often associated with hyperinflation. ${ }^{143,144}$ Obstructive impairment on pulmonary function testing is seen in both PCD and asthma; however, bronchodilator responsiveness, a common feature in asthma, is not typical in children with PCD. ${ }^{131,141}$

\section{Gastroesophageal reflux disease and aspiration}

Gastroesphageal reflux disease may present with a variety of pulmonary and upper respiratory tract symptoms, including cough, wheeze, rhinorrhea, sneezing, and recurrent pneumonia. ${ }^{145,146}$ Aspiration pneumonia (chemical pneumonitis) can occur as a result of gastroesphageal reflux disease, which typically involves upper lobes on chest radiograph, ${ }^{147}$ whereas radiologic findings in $\mathrm{PCD}$ have a predilection for the right middle lobe and lingula. ${ }^{134}$

\section{Immunodeficiency}

Primary immunodeficiencies often present with chronic sinopulmonary infections, resulting in a distinct overlap in symptoms with PCD. ${ }^{148,149}$ The antibody deficiencies seen with humoral diseases result in increased susceptibility to encapsulated bacteria (Staphylococcus aureus, Streptococcus pneumoniae, and Haemophilus influenzae), and lead to recurrent pneumonia, 
Table 4. Differential diagnoses, presenting symptoms, and findings

\begin{tabular}{|c|c|c|c|c|c|c|}
\hline Symptoms & PCD & $\mathrm{CF}$ & Asthma & Allergic rhinitis & GERD & ILD \\
\hline Cough & +++ & +++ & ++ & ++ & ++ & ++ \\
\hline Frequency & Chronic, daily & Chronic & Intermittent & Intermittent & Intermittent & Intermittent \\
\hline Character & Wet & Wet & Dry & Dry or wet & Dry or wet & Dry or wet \\
\hline Time of year & Year-round & Year-round & Often seasonal & Often seasonal & Year-round & Year-round \\
\hline Nasal congestion & +++ & ++ & w/allergic rhinitis & ++ & - & - \\
\hline Frequency & Chronic, daily & Intermittent & & Intermittent & & \\
\hline Time of year & Year-round & Year-round & & Often seasonal & & \\
\hline Otitis media & +++ & - & - & - & + & ++ \\
\hline Sinus disease & +++ & +++ & - & ++ & - & - \\
\hline $\begin{array}{l}\text { Neonatal } \\
\text { respiratory } \\
\text { distress }\end{array}$ & +++ & - & - & - & - & +++ \\
\hline \multicolumn{7}{|l|}{ Findings } \\
\hline Chest imaging & $\begin{array}{l}\text { Hyperinflation, } \\
\text { infiltrates, } \\
\text { atelectasis, } \\
\text { peribronchial } \\
\text { thickening, } \\
\text { bronchiectasis }\end{array}$ & $\begin{array}{l}\text { Hyperinflation, } \\
\text { infiltrates, } \\
\text { atelectasis, } \\
\text { peribronchial } \\
\text { thickening, } \\
\text { bronchiectasis }\end{array}$ & $\begin{array}{l}\text { Hyperinflation, } \\
\text { infiltrates, rare } \\
\text { atelectasis }\end{array}$ & Normal & $\begin{array}{l}\text { Normal, or infiltrates } \\
\text { with aspiration, } \\
\text { rare bronchiectasis }\end{array}$ & $\begin{array}{l}\text { Ground-glass opacities, } \\
\text { hyperlucency, } \\
\text { consolidation, septal } \\
\text { thickening, cysts, } \\
\text { nodules }\end{array}$ \\
\hline $\begin{array}{l}\text { Pulmonary } \\
\text { function } \\
\text { testing }\end{array}$ & $\begin{array}{l}\text { Obstructive, later } \\
\text { mixed }\end{array}$ & $\begin{array}{l}\text { Obstructive, later } \\
\text { mixed }\end{array}$ & Obstructive & Normal & Normal & Restrictive \\
\hline
\end{tabular}

sinus infection, and otitis media with symptoms, which overlap with PCD.

\section{Interstitial lung disease}

ILD is a descriptive term that encompasses a spectrum of over 100 lung diseases of both known and unknown etiology, all of which involve damage of the alveolar wall, accumulation of extracellular matrix within the pulmonary interstitium, and destruction of normal alveolar-capillary complexes, with progression toward pulmonary fibrosis. ${ }^{130,150}$ Patients with ILD may present in infancy or childhood with pulmonary infiltrates, hypoxia, cough, tachypnea, and frequent infections. ${ }^{129,130,150}$ Pulmonary function testing in ILD typically shows restrictive impairment ${ }^{129}$ that is distinct from the obstructive impairment seen in PCD. Typical findings on high-resolution chest CT in ILD include ground-glass opacities, septal thickening, geographic hyperlucency, consolidation, and cysts or nodules, ${ }^{129}$ all of which are distinct from the hyperinflation, atelectasis, infiltrates, bronchial thickening, and bronchiectasis seen in PCD. 9,105

\section{DIAGNOSTIC APPROACH}

The diagnostic approach to PCD is evolving. Until recently, the only definitive diagnostic test had been electron microscopy to define ultrastructural defects in cilia supported by light microscopic analysis demonstrating obvious ciliary dysfunction (immotile or profoundly dyskinetic cilia). Emerging diagnostic tests include genetic testing, nasal NO measurement, immunofluorescent analysis, and high-speed videomicroscopy to define subtle ciliary dysmotility. At this point, these specialized diagnostic tests are not standardized or readily available; therefore, referral to research centers may be needed. A systematic research approach to diagnosing PCD has defined some individuals with normal ciliary ultrastructure, who have PCD based on identification of disease-causing mutations in ciliary genes associated with subtle defects in ciliary motility (as described earlier). It is conceivable that ultrastructural defects may represent a small fraction of individuals with a genetic defect of cilia in PCD.

\section{DIAGNOSTIC TESTS}

\section{Ultrastructural changes in PCD}

Ultrastructural defects of cilia associated with mucociliary dysfunction were first described in 1975 by Afzelius et al.4,151 These reports identified absent and dysmorphic dynein arms in spermatozoa and airway cilia of affected individuals and subsequent reports have supported these observations. Current ciliary ultrastructural diagnostic criteria include absence or structural modification of either IOA or ODAs individually, or of both dynein arms ${ }^{152-155}$ (Fig. 3). Cilia with defective radial spokes and transposition of a peripheral pair of microtubules to occupy the central axis also have been associated with disease consistent with PCD, although such cases seem to be rare. ${ }^{156,157}$ 


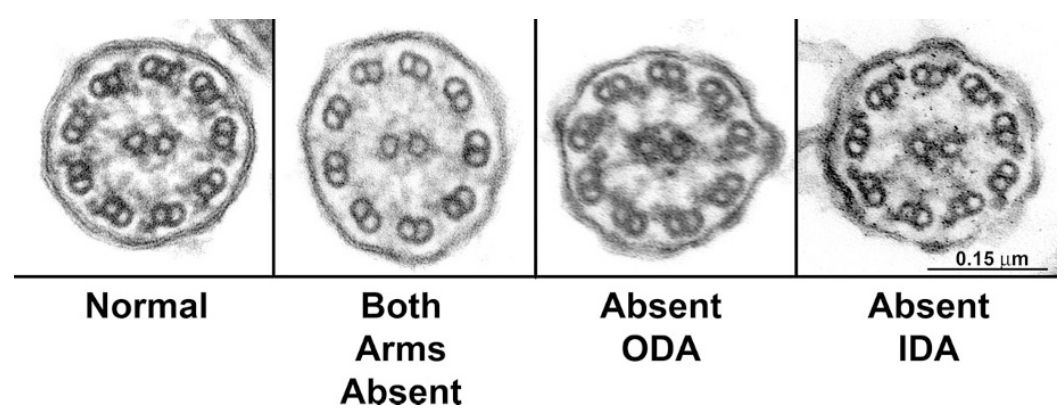

Fig. 3. Electron micrographs of nasal cilia from patients with primary ciliary dyskinesia (PCD) illustrating dynein defects. Far left panel illustrates ultrastructure of a normal cilium from nasal epithelium of a healthy, clinically unaffected subject. The adjacent panels from three different patients with PCD illustrate defects in both dynein arms, isolated defects of outer dynein arms only, and isolated defects of inner dynein arms only.

Although a variety of other ciliary ultrastructural defects such as axonemal changes are reported in respiratory disease, these changes are "secondary" and can be traced to infection, inflammation, or irritant exposure. ${ }^{158,159}$ These abnormalities are distinguished from the index ultrastructural lesions of PCD by their lack of universality in all cilia of affected individuals. Indeed, studies of healthy airways have demonstrated a background of $3-5 \%$ defective cilia even in airways of healthy individuals. ${ }^{160}$ Ultrastructural analysis is cumbersome requiring technical expertise, sophisticated electron optical imaging, and is only available at a limited number of centers.

Although ultrastructural analysis has proved invaluable in the diagnosis of PCD and has been considered the gold standard, new studies ${ }^{37}$ are emerging to demonstrate that affected individuals can exhibit the clinical phenotype of PCD, and mutations in ciliary genes, but have normal ciliary ultrastructure. This observation points to the broadening definition of PCD, which is being brought about by advances in molecular genetics. These molecular studies are important, as they support a growing awareness among researchers that PCD is an underreported syndrome perhaps, in part, because of the limitation of ciliary ultrastructural analysis. ${ }^{161}$

\section{Ciliary motility abnormalities in PCD}

The first reports by Afzelius et al.4,151 indicated spermatozoa and airway cilia from the affected individuals were totally immotile, which led to the early descriptive name, "immotile cilia syndrome." Subsequent studies among other affected individuals reported motile, but dyskinetic, ciliary activity, which led to adoption of "primary ciliary dyskinesia (PCD)." PCD more correctly described the typical pattern of motility and implied a heterogeneous genetic basis of the syndrome. Motile, but dyskinetic, cilia usually beat out of synchrony relative to neighboring cilia. Typically, dyskinesia is accompanied by markedly attenuated ciliary beat frequency $\left(<3 \mathrm{~Hz}\right.$ at $\left.22^{\circ} \mathrm{C}\right)$ although cases of vigorous motility have been documented. Ongoing research is studying relationships between ciliary kinetics and beat frequency, specific ultrastructural characteristics, and specific dynein mutations conferring PCD.

\section{Nasal NO testing}

Nasal NO measurements is emerging as a noninvasive screening test for PCD based on multiple studies demonstrating that nasal NO production is markedly reduced (5-20\% of normal) in patients with PCD. ${ }^{7-10,162}$ The exact mechanism for reduced nasal NO in PCD has yet to be elucidated, and the biologic function of nasal NO has not been fully defined.
Postulated functions include regulation of ciliary motility ${ }^{163}$ and antimicrobial activity. ${ }^{164} \mathrm{Nasal} \mathrm{NO}$, produced predominantly in the paranasal sinuses, is much more abundant (10 to 50 -fold greater) than in the lower airways. ${ }^{10,162,165}$ Consequently, accurate measurement of nasal NO production requires specific techniques for palate closure, to ensure that there is no dilution of the nasal NO by air from the lower airways. ${ }^{134,165}$ Although nasal NO is extremely low in patients with PCD, it is also reduced (though not as low) in patients with CF.134,165 Sinus disease (acute or chronic) may result in falsely diminished nasal NO levels in otherwise healthy subjects. ${ }^{165}$ Because no Food and Drug Administration-approved devices for measurement of nasal NO are available, nasal NO measurement is used predominantly in research studies in the United States but has become part of the diagnostic clinical testing at centers in Europe. ${ }^{166}$ Normal values are published for children as young as 6 years of age. ${ }^{167}$ Recent studies have focused on standardizing techniques for measuring nasal NO especially in children under 6 years of age who are unable to cooperate with maneuvers to close the soft palate. ${ }^{168,169}$

\section{Immunofluorescent analysis}

Immunofluorescent analysis for ciliary proteins holds diagnostic potential for PCD. Recent studies showed that PCD patients with ODA defects had absence of DNAH5 staining from the entire axoneme or from the distal portion and accumulation of DNAH5 at the microtubule-organizing center, in contrast to all control individuals, including disease controls (recurrent respiratory infections unrelated to PCD) who had normal DNAH5 staining along the ciliary axoneme. ${ }^{52,170}$ This method is performed on nasal epithelial cells obtained via noninvasive trans-nasal brushing. The main advantage of this method is that it can detect the changes along the entire length of the ciliary axoneme. At present immunofluorescent staining is available at one research laboratory in Germany with a limited supply of ciliary protein-specific antibodies.

\section{Genetic testing}

The diagnosis of PCD is challenging due to the requirement of cumbersome ultrastructural or immunofluorescent analyses, and only a few laboratories can offer those tests. Defining biallelic mutations in trans (inheriting a mutation from each parent) in a patient with PCD in the causative gene would confirm the diagnosis. But, genetic diagnosis for PCD is also challenging due to the genetic heterogeneity and the large size of PCD-causing genes. In addition, despite the identification of several of PCD causing genes, the number of patients with PCD 
harboring mutations in some of these genes is small and thus, limits the development of a robust clinical genetic test. DNAII and DNAH5 seem to be major causative genes in almost $30-$ $38 \%$ of all PCD families. ${ }^{33,36,44-46,48,51}$ Because mutations in these genes have been exclusively identified in patients with ODA defects, the mutation detection rate is higher $(\sim 50-60 \%)$ in patients with PCD with ODA defects. Despite allelic heterogeneity in DNAI1 and DNAH5, mutation clusters were observed in nine exons of DNAI1 (exons 1, 13, 16, and 17) and DNAH5 (exons 34, 50, 63, 76, and 77). On the basis of the published reports, we estimate that analysis of the nine exons would lead to the identification of at least one mutant allele in approximately $24 \%$ of all patients with PCD. The DNA from these patients can then be sequenced to test for the second mutation. The first PCD clinical genetic assay was developed that required sequencing of only nine exons (of 100 exons), ${ }^{28,47}$ and a commercial laboratory subsequently developed a genetic assay that tests for the known 60 mutant alleles of DNAII and DNAH5. For the full listing of the laboratories offering PCD genetic tests please check http://www.genetests.org/. Sequencebased assays are expensive; hence, alternative approaches are being considered, such as melting curve analysis and microarray chips. The benefit of these alternative methods is the ease of addition of the new genetic mutations as they are discovered, which can assist in further increase in specificity of the genetic test.

\section{MANAGEMENT}

\section{Medical management of lung disease}

Currently, there are no therapies that have been adequately studied to definitively prove their efficacy in the treatment of PCD. Treatments that are used in clinical practice tend to be extrapolated from CF clinical trials. There is evidence, however, from the observational data of clinical case series that early diagnosis and management of patients with PCD in a specialized PCD clinic may improve long-term lung function outcomes. ${ }^{171}$ The disease management approach reported by Ellerman and Bisgaard ${ }^{171}$ followed an algorithm very similar to the CF disease management approach. A number of high-quality randomized controlled trials of therapy have been published to help establish an evidence-based approach to care of CF. ${ }^{172} \mathrm{CF}$ medical management practices, which have some biological rationale for extrapolation to $\mathrm{PCD}$, include daily airway clearance, judicious use of antibiotics, infection control and attention to nutritional status. Generally, antibiotics are used acutely with disease exacerbation and are prescribed according to bacteria grown in the last sputum culture. Chronic suppressive use of antibiotics would be considered, if a patient is repeatedly growing Pseudomonas aeruginosa in the sputum. There are no data to recommend for or against agents that improve mucociliary clearance or inflammation in PCD. Clinical utility of bronchodilators has not been demonstrated in PCD. Monitoring for progression of lung disease should be an important part of the regular clinic visit. At present, there are no clinical practice guidelines to direct frequency of clinic visits or additional testing. Based on the PCD management approach reported by Ellerman and Bisgaard ${ }^{171}$ and clinical practices used for $\mathrm{CF}$, tests to consider include lung function testing and respiratory cultures every 3-6 months and lung imaging on an annual or biannual basis. Consideration should be given for obtaining a chest CT, instead of a plain chest radiograph, at the time of diagnosis or at intervals during follow-up, because chest CT is the gold standard for diagnosing bronchiectasis. ${ }^{173}$ The addi- tional radiation of a chest CT must be weighed against the potential "benefit" of early recognition of bronchiectasis.

\section{Surgical management of lung disease}

Lobectomy is generally not recommended because PCD is a generalized airway disease. However, lobectomy has been shown to improve symptoms and to have low-perioperative mortality in case series of selected patients with PCD $^{174}$ and idiopathic bronchiectasis. ${ }^{175}$ Consideration for lobectomy should be limited to selected patients with severe localized bronchiectasis with frequent febrile episodes or, severe hemoptysis and failure of conservative medical management with antibiotics, airway clearance, and embolotherapy. ${ }^{174}$ Surgery should only be performed in centers with specialized expertise. Lung transplantation is an option once a patient has reached end-stage lung disease. There are at least nine reported cases of successful lung transplantation in patients with PCD. ${ }^{176}$ There are no longitudinal survival data published to develop criteria for referral for lung transplantation in PCD.

\section{Management of chronic otitis media}

The management of serous otitis and recurrent otitis media in PCD is controversial. Although some otolaryngologists argue that myringotomy tubes can be harmful and should be avoided, others argue that myringotomy tubes allow hearing and speech to develop in the infant or toddler with hearing loss due to chronic serous otitis. The proponents against tubes suggest that they cause annoying chronic mucopurulent drainage of the middle ear, pose a risk of chronic middle ear perforation and that the natural history of hearing loss is that it normalizes by age 12 years, making these procedures unnecessary. ${ }^{177}$ On the other hand, mucopurulent drainage responds to treatment with local antibiotics and there is no hard data to show that chronic middle ear perforation is a common complication. In addition, delayed speech development can have profound effects on language development and subsequent school performance. Hearing aids may be used instead of myringotomy tubes; however, they are sometimes not well tolerated in the preschool age group.

\section{Specialized PCD diagnostic and treatment centers}

A multidisciplinary "disease management" approach to chronic disease is now well recognized to be the most successful strategy for improving patient outcomes. ${ }^{178}$ Key elements of advancing disease management include research, performance measurement, and quality improvement. ${ }^{179}$ When one considers that PCD is a chronic airways disease with many similarities to CF including a similar (albeit slower) progression of lung function deterioration and lower airways bacterial colonization with age, 9 the notion of a need for specialty "PCD Centers" seems obvious. Improvement in survival and quality of life over the last 30 years for patients with CF can be largely attributed to the better treatment developed at major CF centers. ${ }^{180}$ In addition to improved clinical outcomes, disease-specific centers are generally regarded favorably by patients and have numerous psychosocial benefits, including the opportunity to meet other families/patients with the same rare disease and share experiences. ${ }^{181}$ Finally, major CF centers also provide a natural infrastructure for the conduct of clinical research to further improve outcomes. ${ }^{139}$ Good medical management in a specialized PCD diagnostic and treatment center will probably provide the patient with PCD with the best chance for preservation of lung function over time. 


\section{ACKNOWLEDGMENTS}

M.W.L., J.L.C., T.W.F., S.D.D., S.D.D., M.R.K., and M.A.Z. are supported by National Institutes of Health Grant U54RR019480, M.R.K. and M.A.Z. are supported by National Institutes of Health Grant R01 HL071798, T.W.F. is supported by R01 HL08265 and Children's Discovery Institute, J.E.P. is supported by National Institutes of Health training Grant 5 T32 HL 007106-32, J.L.C. is supported by Clinical Innovator Award by Flight Attendant Medical Research Institute. We are indebted to the patients with PCD and their families, and thank Ms. Michele Manion, who founded the US PCD Foundation. We are indebted to the principal investigators and the coordinators of the "Genetic Disorders of Mucociliary Clearance Consortium" that is part of the Rare Disease Clinical Research Network (http://rarediseasesnetwork. epi.usf.edu/gdmcc/index.htm), including Dr. Kenneth Olivier, Ms. Reginald Claypool, MS. Tanya Glaser, Ms. Kate Birkenkamp, and Ms. Beth Melia (National Institute of Allergy and Infectious Diseases, Bethesda, MD), Dr. Jeffrey Atkinson and Ms. Jane Quante (Washington University in St. Louis, Mo), Dr. Scott Sagel and Ms. Shelley Mann (The Children's Hospital Colorado, Denver, CO), Drs. Margaret Rosenfeld, Ronald Gibson, and Moira Aitken and Ms. Sharon McNamara (Children's Hospital and Regional Medical Center, Seattle, WA), Dr. Carlos Milla and Ms. Jacquelyn Zirbez (Stanford University Medical Center, Palo Alto, CA), Ms. Susan Minnix (The University of North Carolina at Chapel Hill, NC), and Ms. Donna Wilkes (The Hospital for Sick Children, Toronto, Ontario, Canada). In addition, all the authors belong to this consortium. Authors thank Drs. Karen Weck, Jessica Booker, and Kay Chao (Molecular Genetics Laboratory, UNC Hospitals, NC) for the continued work on PCD clinical genetics testing. Authors also thank Drs. Milan Hazucha, Larry Ostrowski, Peadar Noone, Adriana Lori, Hilda Metjian, Deepika Polineni, Adam Shapiro, Ms. Kim Burns, Mr. Michael Chris Armstrong, Mr. Kunal Chawla, Ms. Elizabeth Godwin and Ms. Cindy Sell from the University of North Carolina at Chapel Hill, NC. We also thank Dr. Peter Satir (Albert Einstein College of Medicine, Bronx, NY) for providing information regarding the primary cilium structure.

\section{REFERENCES}

1. Katsuhara K, Kawamoto S, Wakabayashi T, Belsky JL. Situs inversus totalis and Kartagener's syndrome in a Japanese population. Chest 1972;61:56-61.

2. Torgersen J. Situs inversus, asymmetry, and twinning. Am J Hum Genet 1950;2:361-370

3. Kartagener M. Zur pathogenese der bronkiectasien: bronkiectasien bei situs viscerum inversus. Beitr Klin Tuberk 1933;82:489-501.

4. Afzelius BA. A human syndrome caused by immotile cilia. Science 1976; 193:317-319.

5. Eliasson R, Mossberg B, Camner P, Afzelius BA. The immotile-cilia syndrome. A congenital ciliary abnormality as an etiologic factor in chronic airway infections and male sterility. N Engl J Med 1977;297:1-6.

6. Pedersen H, Mygind N. Absence of axonemal arms in nasal mucosa cilia in Kartagener's syndrome. Nature 1976;262:494-495.

7. Corbelli R, Bringolf-Isler B, Amacher A, Sasse B, Spycher M, Hammer J. Nasal nitric oxide measurements to screen children for primary ciliary dyskinesia. Chest 2004;126:1054-1059.

8. Narang I, Ersu R, Wilson NM, Bush A. Nitric oxide in chronic airway inflammation in children: diagnostic use and pathophysiological significance. Thorax 2002;57:586-589.

9. Noone PG, Leigh MW, Sannuti A, et al. Primary ciliary dyskinesia: diagnostic and phenotypic features. Am J Respir Crit Care Med 2004;169:459-467.

10. Wodehouse T, Kharitonov SA, Mackay IS, Barnes PJ, Wilson R, Cole PJ. Nasal nitric oxide measurements for the screening of primary ciliary dyskinesia. Eur Respir J 2003;21:43-47.

11. Goodenough UW, Heuser JE. Outer and inner dynein arms of cilia and flagella. Cell 1985;41:341-342.

12. Mastronarde DN, O'Toole ET, McDonald KL, McIntosh JR, Porter ME. Arrangement of inner dynein arms in wild-type and mutant flagella of Chlamydomonas. J Cell Biol 1992;118:1145-1162.

13. Satir P, Christensen ST. Overview of structure and function of mammalian cilia. Annu Rev Physiol 2007;69:377-400.
14. Gilula NB, Satir P. The ciliary necklace. A ciliary membrane specialization. J Cell Biol 1972;53:494-509.

15. Carson JL, Collier AM, Knowles MR, Boucher RC, Rose JG. Morphometric aspects of ciliary distribution and ciliogenesis in human nasal epithelium. Proc Natl Acad Sci USA 1981;78:6996-6999.

16. Zhou H, Wang X, Brighton L, Hazucha M, Jaspers I, Carson JL. Increased nasal epithelial ciliary beat frequency associated with lifestyle tobacco smoke exposure. Inhal Toxicol. Available at: http://informapharmascience. com/iht. Accessed May 2, 2009.

17. Li D, Shirakami G, Zhan X, Johns RA. Regulation of ciliary beat frequency by the nitric oxide-cyclic guanosine monophosphate signaling pathway in rat airway epithelial cells. Am J Respir Cell Mol Biol 2000;23:175-181.

18. Wyatt TA, Spurzem JR, May K, Sisson JH. Regulation of ciliary beat frequency by both PKA and PKG in bovine airway epithelial cells. Am J Physiol 1998;275:L827-L835.

19. Dirksen ER, Sanderson MJ. Regulation of ciliary activity in the mammalian respiratory tract. Biorheology 1990;27:533-545.

20. Sanderson MJ, Dirksen ER. Mechanosensitive and beta-adrenergic control of the ciliary beat frequency of mammalian respiratory tract cells in culture. Am Rev Respir Dis 1989;139:432-440.

21. Pazour GJ, Witman GB. The vertebrate primary cilium is a sensory organelle. Curr Opin Cell Biol 2003;15:105-110.

22. Pazour GJ, Agrin N, Walker BL, Witman GB. Identification of predicted human outer dynein arm genes-candidates for primary ciliary dyskinesia genes. J Med Genet 2006;43:62-73.

23. Huang K, Diener DR, Mitchell A, Pazour GJ, Witman GB, Rosenbaum JL. Function and dynamics of PKD2 in Chlamydomonas reinhardtii flagella. J Cell Biol 2007;179:501-514.

24. Pazour GJ, Dickert BL, Vucica Y, et al. Chlamydomonas IFT88 and its mouse homologue, polycystic kidney disease gene $\operatorname{tg} 737$, are required for assembly of cilia and flagella. J Cell Biol 2000;151:709-718.

25. Beales PL, Bland E, Tobin JL, et al. IFT80, which encodes a conserved intraflagellar transport protein, is mutated in Jeune asphyxiating thoracic dystrophy. Nat Genet 2007:39:727-729.

26. Badano JL, Mitsuma N, Beales PL, Katsanis N. The ciliopathies: an emerging class of human genetic disorders. Annu Rev Genomics Hum Genet 2006; $7: 125-148$

27. Fliegauf M, Benzing T, Omran H. When cilia go bad: cilia defects and ciliopathies. Nat Rev Mol Cell Biol 2007;8:880-893.

28. Zariwala MA, Knowles MR, Omran H. Genetic defects in ciliary structure and function. Annu Rev Physiol 2007;69:423-450.

29. Blouin JL, Meeks M, Radhakrishna U, et al. Primary ciliary dyskinesia: a genome-wide linkage analysis reveals extensive locus heterogeneity. Eur $J$ Hum Genet 2000;8:109-118.

30. Bartoloni L, Blouin JL, Pan Y, et al. Mutations in the DNAH11 (axonemal heavy chain dynein type 11) gene cause one form of situs inversus totalis and most likely primary ciliary dyskinesia. Proc Natl Acad Sci USA 2002;99: 10282-10286.

31. Duriez B, Duquesnoy P, Escudier E, et al. A common variant in combination with a nonsense mutation in a member of the thioredoxin family causes primary ciliary dyskinesia. Proc Natl Acad Sci USA 2007;104: 3336-3341

32. Omran H, Kobayashi D, Olbrich H, et al. Ktu/PF13 is required for cytoplasmic pre-assembly of axonemal dyneins. Nature 2008;456:611-616.

33. Pennarun G, Escudier E, Chapelin C, et al. Loss-of-function mutations in a human gene related to Chlamydomonas reinhardtii dynein IC78 result in primary ciliary dyskinesia. Am J Hum Genet 1999;65:1508-1519.

34. Pennarun G, Chapelin C, Escudier E, et al. The human dynein intermediate chain 2 gene (DNAI2): cloning, mapping, expression pattern, and evaluation as a candidate for primary ciliary dyskinesia. Hum Genet 2000;107:642-649.

35. Loges NT, Olbrich H, Fenske L, et al. DNAI2 mutations cause primary ciliary dyskinesia with defects in the outer dynein arm. Am J Hum Genet 2008;83:547-558

36. Olbrich H, Haffner K, Kispert A, et al. Mutations in DNAH5 cause primary ciliary dyskinesia and randomization of left-right asymmetry. Nat Genet 2002;30:43-44.

37. Schwabe GC, Hoffmann K, Loges NT, et al. Primary ciliary dyskinesia associated with normal axoneme ultrastructure is caused by DNAHII mutations. Hum Mutat 2008;29:289-298

38. Fliegauf M, Omran H. Novel tools to unravel molecular mechanisms in cilia-related disorders. Trends Genet 2006;22:241-245.

39. Li JB, Gerdes JM, Haycraft CJ, et al. Comparative genomics identifies a flagellar and basal body proteome that includes the BBS5 human disease gene. Cell 2004;117:541-552.

40. Luck DJ. Genetic and biochemical dissection of the eucaryotic flagellum. J Cell Biol 1984;98:789-794.

41. Ostrowski LE, Blackburn K, Radde KM, et al. A proteomic analysis of human cilia: identification of novel components. Mol Cell Proteomics 2002; 1:451-465.

42. Pazour GJ, Agrin N, Leszyk J, Witman GB. Proteomic analysis of a eukaryotic cilium. J Cell Biol 2005;170:103-113. 
43. Piperno G, Huang B, Luck DJ. Two-dimensional analysis of flagellar proteins from wild-type and paralyzed mutants of Chlamydomonas reinhardtii. Proc Natl Acad Sci USA 1977;74:1600-1604.

44. Guichard C, Harricane MC, Lafitte JJ, et al. Axonemal dynein intermediatechain gene (DNAI1) mutations result in situs inversus and primary ciliary dyskinesia (Kartagener syndrome). Am J Hum Genet 2001;68:1030-1035.

45. Zariwala M, Noone PG, Sannuti A, et al. Germline mutations in an intermediate chain dynein cause primary ciliary dyskinesia. Am J Respir Cell Mol Biol 2001;25:577-583.

46. Zariwala MA, Leigh MW, Ceppa F, et al. Mutations of DNAII in primary ciliary dyskinesia: evidence of founder effect in a common mutation. Am J Respir Crit Care Med 2006;174:858-866.

47. Zariwala M, Knowles M, Leigh MW. Primary ciliary dyskinesia, 2007. GeneReviews at GeneTests: Medical Genetics information Resource [database online]. Copyrights University of Washington, Seattle, 1993-2009. Available at: http://www.ncbi.nlm.nih.gov/bookshelf/br.fcgi?book=gene\&partpcd. Accessed April 16, 2009.

48. Failly M, Saitta A, Munoz A, et al. DNAI1 mutations explain only $2 \%$ of primary ciliary dyskinesia. Respiration 2008;76:198-204.

49. Omran H, Haffner K, Volkel A, et al. Homozygosity mapping of a gene locus for primary ciliary dyskinesia on chromosome $5 \mathrm{p}$ and identification of the heavy dynein chain DNAH5 as a candidate gene. Am J Respir Cell Mol Biol 2000;23:696-702.

50. Bush A, Ferkol T. Movement: the emerging genetics of primary ciliary dyskinesia. Am J Respir Crit Care Med 2006;174:109-110.

51. Hornef N, Olbrich H, Horvath J, et al. DNAH5 mutations are a common cause of primary ciliary dyskinesia with outer dynein arm defects. Am J Respir Crit Care Med 2006;174:120-126.

52. Fliegauf M, Olbrich H, Horvath J, et al. Mislocalization of DNAH5 and DNAH9 in respiratory cells from patients with primary ciliary dyskinesia. Am J Respir Crit Care Med 2005;171:1343-1349.

53. Bartoloni L, Mitchison H, Pazour GJ, et al. No deleterious mutations were found in three genes (HFH4, LC8, IC2) on human chromosome $17 \mathrm{q}$ in patients with primary ciliary dyskinesia. Eur J Hum Genet 2000;8:P-484 (Abstract).

54. Supp DM, Witte DP, Potter SS, Brueckner M. Mutation of an axonemal dynein affects left-right asymmetry in inversus viscerum mice. Nature 1997; 389:963-966.

55. Supp DM, Brueckner M, Kuehn MR, et al. Targeted deletion of the ATP binding domain of left-right dynein confirms its role in specifying development of left-right asymmetries. Development 1999;126:5495-5504.

56. Castleman VH, Romio L, Chodhari R, et al. Mutations in radial spoke head protein genes $R S P H 9$ and $R S P H 4 A$ cause primary ciliary dyskinesia with central-microtubular-pair abnormalities. Am J Hum Genet 2009;84: 197-209.

57. Yang P, Diener DR, Yang C, et al. Radial spoke proteins of Chlamydomonas flagella. J Cell Sci 2006;119:1165-1174.

58. Curry AM, Williams BD, Rosenbaum JL. Sequence analysis reveals homology between two proteins of the flagellar radial spoke. Mol Cell Biol 1992;12:3967-3977.

59. Budny B, Chen W, Omran H, et al. A novel X-linked recessive mental retardation syndrome comprising macrocephaly and ciliary dysfunction is allelic to oral-facial-digital type I syndrome. Hum Genet 2006;120:171-178.

60. Ferrante MI, Zullo A, Barra A, et al. Oral-facial-digital type I protein is required for primary cilia formation and left-right axis specification. Nat Genet 2006;38:112-117.

61. Romio L, Fry AM, Winyard PJ, Malcolm S, Woolf AS, Feather SA. OFD1 is a centrosomal/basal body protein expressed during mesenchymal-epithelial transition in human nephrogenesis. J Am Soc Nephrol 2004;15:2556-2568.

62. Moore A, Escudier E, Roger G, et al. RPGR is mutated in patients with a complex X-linked phenotype combining primary ciliary dyskinesia and retinitis pigmentosa. $J$ Med Genet 2006;43:326-333.

63. Zito I, Downes SM, Patel RJ, et al. RPGR mutation associated with retinitis pigmentosa, impaired hearing, and sinorespiratory infections. J Med Genet 2003;40:609-615.

64. Iannaccone A, Breuer DK, Wang XF, et al. Clinical and immunohistochemical evidence for an $\mathrm{X}$ linked retinitis pigmentosa syndrome with recurrent infections and hearing loss in association with an $R P G R$ mutation. $J$ Med Genet 2003;40:e118.

65. Hong DH, Pawlyk BS, Adamian M, Sandberg MA, Li T. A single, abbreviated RPGR-ORF15 variant reconstitutes RPGR function in vivo. Invest Ophthalmol Vis Sci 2005;46:435-441.

66. Hong DH, Pawlyk B, Sokolov M, et al. RPGR isoforms in photoreceptor connecting cilia and the transitional zone of motile cilia. Invest Ophthalmol Vis Sci 2003;44:2413-2421.

67. De Scally M, Lobetti RG, Van Wilpe E. Primary ciliary dyskinesia in a Staffordshire bull terrier. J S Afr Vet Assoc 2004;75:150-152.

68. Edwards DF, Patton CS, Kennedy JR. Primary ciliary dyskinesia in the dog. Probl Vet Med 1992;4:291-319.

69. Neil JA, Canapp SO Jr, Cook CR, Lattimer JC. Kartagener's syndrome in a Dachshund dog. J Am Anim Hosp Assoc 2002;38:45-49.
70. Reichler IM, Hoerauf A, Guscetti F, et al. Primary ciliary dyskinesia with situs inversus totalis, hydrocephalus internus and cardiac malformations in a dog. J Small Anim Pract 2001;42:345-348.

71. Watson PJ, Herrtage ME, Peacock MA, Sargan DR. Primary ciliary dyskinesia in Newfoundland dogs. Vet Rec 1999;144:718-725.

72. Roperto F, Galati P, Maiolino P, Papparella S. Atypical basal bodies in the oviductal mucosa (ampulla) of gilts with primary ciliary dyskinesia (PCD). J Submicrosc Cytol Pathol 1990;22:587-589.

73. Roperto F, Galati P, Troncone A, Rossacco P, Campofreda M. Primary ciliary dyskinesia in pigs. J Submicrosc Cytol Pathol 1991;23:233-236.

74. Torikata C, Kijimoto C, Koto M. Ultrastructure of respiratory cilia of WIC-Hyd male rats. An animal model for human immotile cilia syndrome. Am J Pathol 1991;138:341-347.

75. Ibanez-Tallon I, Gorokhova S, Heintz N. Loss of function of axonemal dynein Mdnah5 causes primary ciliary dyskinesia and hydrocephalus. Hum Mol Genet 2002;11:715-721.

76. Tan SY, Rosenthal J, Zhao XQ, et al. Heterotaxy and complex structural heart defects in a mutant mouse model of primary ciliary dyskinesia. $J$ Clin Invest 2007:117:3742-3752.

77. Layton WM Jr. Random determination of a developmental process: reversal of normal visceral asymmetry in the mouse. J Hered 1976;67:336-338.

78. McNeish JD, Thayer J, Walling K, Sulik KK, Potter SS, Scott WJ. Phenotypic characterization of the transgenic mouse insertional mutation, legless. J Exp Zool 1990;253:151-162.

79. Singh G, Supp DM, Schreiner C, et al. legless insertional mutation: morphological, molecular, and genetic characterization. Genes Dev 1991;5: 2245-2255.

80. Kobayashi Y, Watanabe M, Okada Y, et al. Hydrocephalus, situs inversus, chronic sinusitis, and male infertility in DNA polymerase lambda-deficient mice: possible implication for the pathogenesis of immotile cilia syndrome. Mol Cell Biol 2002;22:2769-2776.

81. Lee L, Campagna DR, Pinkus JL, et al. Primary ciliary dyskinesia in mice lacking the novel ciliary protein Pcdp1. Mol Cell Biol 2008;28:949-957.

82. Davy BE, Robinson ML. Congenital hydrocephalus in hy3 mice is caused by a frameshift mutation in Hydin, a large novel gene. Hum Mol Genet 2003; 12:1163-1170

83. Lechtreck KF, Delmotte P, Robinson ML, Sanderson MJ, Witman GB. Mutations in Hydin impair ciliary motility in mice. J Cell Biol 2008;180: 633-643.

84. Robinson ML, Allen CE, Davy BE, et al. Genetic mapping of an insertional hydrocephalus-inducing mutation allelic to hy3. Mamm Genome 2002;13: $625-632$.

85. Smith EF. Hydin seek: finding a function in ciliary motility. $J$ Cell Biol 2007; 176:403-404.

86. Tanaka H, Iguchi N, Toyama Y, et al. Mice deficient in the axonemal protein Tektin-t exhibit male infertility and immotile-cilium syndrome due to impaired inner arm dynein function. Mol Cell Biol 2004;24:7958-7964.

87. Neesen J, Kirschner R, Ochs M, et al. Disruption of an inner arm dynein heavy chain gene results in asthenozoospermia and reduced ciliary beat frequency. Hum Mol Genet 2001;10:1117-1128.

88. Vernon GG, Neesen J, Woolley DM. Further studies on knockout mice lacking a functional dynein heavy chain $(M D H C 7)$. 1. Evidence for a structural deficit in the axoneme. Cell Motil Cytoskeleton 2005;61:65-73.

89. Maiti AK, Bartoloni L, Mitchison HM, et al. No deleterious mutations in the FOXJ1 (alias HFH-4) gene in patients with primary ciliary dyskinesia (PCD). Cytogenet Cell Genet 2000;90:119-122.

90. Zhang Z, Sapiro R, Kapfhamer D, et al. A sperm-associated WD repeat protein orthologous to Chlamydomonas PF20 associates with Spag6, the mammalian orthologue of Chlamydomonas PF16. Mol Cell Biol 2002;22: 7993-8004.

91. Zhang Z, Kostetskii I, Tang W, et al. Deficiency of SPAG16L causes male infertility associated with impaired sperm motility. Biol Reprod 2006;74: 751-759.

92. Zhang Z, Zariwala MA, Mahadevan MM, et al. A heterozygous mutation Disrupting the SPAG16 gene results in biochemical instability of central apparatus components of the human sperm axoneme. Biol Reprod 2007;77: 871 .

93. Sapiro R, Kostetskii I, Olds-Clarke P, Gerton GL, Radice GL, Strauss JF III. Male infertility, impaired sperm motility, and hydrocephalus in mice deficient in sperm-associated antigen 6. Mol Cell Biol 2002;22:6298-6305.

94. Zhang Z, Tang W, Zhou R, et al. Accelerated mortality from hydrocephalus and pneumonia in mice with a combined deficiency of SPAG6 and SPAG16L reveals a functional interrelationship between the two central apparatus proteins. Cell Motil Cytoskeleton 2007;64:360-376.

95. Ibanez-Tallon I, Pagenstecher A, Fliegauf M, et al. Dysfunction of axonemal dynein heavy chain Mdnah5 inhibits ependymal flow and reveals a novel mechanism for hydrocephalus formation. Hum Mol Genet 2004;13:21332141.

96. Zariwala M, O'Neal WK, Noone PG, Leigh MW, Knowles MR, Ostrowski LE. Investigation of the possible role of a novel gene, $D P C D$, in primary ciliary dyskinesia Am J Respir Cell Mol Biol 2004;30:428-434. 
97. Bertocci B, De Smet A, Berek C, Weill JC, Reynaud CA. Immunoglobulin kappa light chain gene rearrangement is impaired in mice deficient for DNA polymerase Mu. Immunity 2003;19:203-211.

98. Sleigh MA, Blake JR, Liron N. The propulsion of mucus by cilia. Am Rev Respir Dis 1988;137:726-741.

99. Knowles MR, Boucher RC. Mucus clearance as a primary innate defense mechanism for mammalian airways. J Clin Invest 2002;109:571-577.

100. Wanner A, Salathe M, O'Riordan TG. Mucociliary clearance in the airways. Am J Respir Crit Care Med 1996;154:1868-1902.

101. Bush A, Cole P, Hariri M, et al. Primary ciliary dyskinesia: diagnosis and standards of care. Eur Respir J 1998;12:982-988.

102. Ferkol T, Leigh M. Primary ciliary dyskinesia and newborn respiratory distress. Semin Perinatol 2006;30:335-340.

103. Hossain T, Kappelman MD, Perez-Atayde AR, Young GJ, Huttner KM, Christou H. Primary ciliary dyskinesia as a cause of neonatal respiratory distress: implications for the neonatologist. J Perinatol 2003;23:684-687.

104. Coren ME, Meeks M, Morrison I, Buchdahl RM, Bush A. Primary ciliary dyskinesia: age at diagnosis and symptom history. Acta Paediatr 2002;91: 667-669.

105. Jain K, Padley SP, Goldstraw EJ, et al. Primary ciliary dyskinesia in the paediatric population: range and severity of radiological findings in a cohort of patients receiving tertiary care. Clin Radiol 2007;62:986-993.

106. Pittman JE, Davis SD, chawla KK, Knowles MR, Leigh MW, Brown DE. Primary ciliary dyskinesia: characteristics of disease in children under six. Am J Respir Crit Care Med 2008;177:A798 (Abstract).

107. Morini F, Cozzi DA, Conforti A, et al. An infant with respiratory distress and failure to thrive. Eur Respir $J$ 2002;20:500-503.

108. Brueckner M. Cilia propel the embryo in the right direction. Am J Med Genet 2001;101:339-344.

109. El Zein L, Omran H, Bouvagnet P. Lateralization defects and ciliary dyskinesia: lessons from algae. Trends Genet 2003;19:162-167.

110. Kennedy MP, Omran H, Leigh MW, et al. Congenital heart disease and other heterotaxic defects in a large cohort of patients with primary ciliary dyskinesia. Circulation 2007;115:2814-2821.

111. Raman R, Al Ali SY, Poole CA, Dawson BV, Carman JB, Calder L. Isomerism of the right atrial appendages: clinical, anatomical, and microscopic study of a long-surviving case with asplenia and ciliary abnormalities. Clin Anat 2003;16:269-276.

112. Hadfield PJ, Rowe-Jones JM, Bush A, Mackay IS. Treatment of otitis media with effusion in children with primary ciliary dyskinesia. Clin Otolaryngol Allied Sci 1997;22:302-306.

113. Noone PG, Bennett WD, Regnis JA, et al. Effect of aerosolized uridine-5' triphosphate on airway clearance with cough in patients with primary ciliary dyskinesia. Am J Respir Crit Care Med 1999;160:144-149.

114. Kennedy MP, Noone PG, Leigh MW, et al. High-resolution CT of patients with primary ciliary dyskinesia. AJR Am J Roentgenol 2007;188:1232-1238.

115. Nadel HR, Stringer DA, Levison H, Turner JA, Sturgess JM. The immotile cilia syndrome: radiological manifestations. Radiology 1985;154:651-655.

116. Brown DE, Pittman JE, Leigh MW, Fordham L, Davis SD. Early lung disease in young children with primary ciliary dyskinesia. Pediatr Pulmonol 2008;43:514-516.

117. Sweeney TD, Tryka AF, Brain JD. Effect of exercise on redistribution and clearance of inhaled particles from hamster lungs. J Appl Physiol 1990;68: 967-972.

118. Graeter T, Schafers HJ, Wahlers T, Borst HG. Lung transplantation in Kartagener's syndrome. J Heart Lung Transplant 1994;13:724-726.

119. McManus IC, Mitchison HM, Chung EM, Stubbings GF, Martin N. Primary ciliary dyskinesia (Siewert's/Kartagener's syndrome): respiratory symptoms and psycho-social impact. BMC Pulm Med 2003;3:4.

120. Afzelius BA, Eliasson R. Male and female infertility problems in the immotile-cilia syndrome. Eur J Respir Dis Suppl 1983;127:144-147.

121. Munro NC, Currie DC, Lindsay KS, et al. Fertility in men with primary ciliary dyskinesia presenting with respiratory infection. Thorax 1994;49: 684-687.

122. Halbert SA, Patton DL, Zarutskie PW, Soules MR. Function and structure of cilia in the fallopian tube of an infertile woman with Kartagener's syndrome. Hum Reprod 1997;12:55-58.

123. De Santi MM, Magni A, Valletta EA, Gardi C, Lungarella G. Hydrocephalus, bronchiectasis, and ciliary aplasia. Arch Dis Child 1990;65:543-544

124. Greenstone MA, Jones RW, Dewar A, Neville BG, Cole PJ. Hydrocephalus and primary ciliary dyskinesia. Arch Dis Child 1984;59:481-482.

125. Krawczynski MR, Dmenska H, Witt M. Apparent X-linked primary ciliary dyskinesia associated with retinitis pigmentosa and a hearing loss. $J$ Appl Genet 2004;45:107-110.

126. Driscoll JA, Bhalla S, Liapis H, Ibricevic A, Brody SL. Autosomal dominant polycystic kidney disease is associated with an increased prevalence of radiographic bronchiectasis. Chest 2008;133:1181-1188.

127. Gnanaratnem J, Finer NN. Neonatal acute respiratory failure. Curr Opin Pediatr 2000;12:227-232.

128. Cole FS, Hamvas A, Nogee LM. Genetic disorders of neonatal respiratory function. Pediatr Res 2001;50:157-162.
129. Fan LL, Deterding RR, Langston C. Pediatric interstitial lung disease revisited. Pediatr Pulmonol 2004;38:369-378.

130. Leland LF, Claire L. Interstitial lung disease. In: Chernick V, Boat TF, Wilmott RW, Bush A, editors. Kendig's disorders of the respiratory tract in children. Philadelphia: Saunders Elsevier, 2006:666-675.

131. Bush A, Chodhari R, Collins N, et al. Primary ciliary dyskinesia: current state of the art. Arch Dis Child 2007;92:1136-1140.

132. Eriksson M, Ansved T, Anvret M, Carey N. A mammalian radial spokehead-like gene, RSHL1, at the myotonic dystrophy-1 locus Biochem Biophys Res Commun 2001;281:835-841.

133. Brueckner M. Heterotaxia, congenital heart disease, and primary ciliary dyskinesia. Circulation 2007;115:2793-2795.

134. Leigh MW. Primary ciliary dyskinesia. In: Chernick V, Boat TF, Wilmott RW, Bush A, editors. Disorders of the respiratory tract of children. Philadelphia: Saunders-Elsevier, 2006:902-909.

135. Davis PB. Cystic fibrosis. Pediatr Rev 2001;22:257-264.

136. Phillips GE, Thomas S, Heather S, Bush A. Airway response of children with primary ciliary dyskinesia to exercise and beta2-agonist challenge. Eur Respir J 1998;11:1389-1391.

137. Rosenfeld M, Gibson RL, McNamara S, et al. Early pulmonary infection, inflammation, and clinical outcomes in infants with cystic fibrosis. Pediatr Pulmonol 2001;32:356-366.

138. Davies JC, Alton EW, Bush A. Cystic fibrosis. BMJ 2007;335:1255-1259.

139. Davis PB. Cystic fibrosis since 1938. Am J Respir crit care med 2006;173: 475-482.

140. Bacharier LB, Boner A, Carlsen KH, et al. Diagnosis and treatment of asthma in childhood: a PRACTALL consensus report. Allergy 2008;63: $5-34$

141. Kercsmar CM. Wheezing in older children: asthma. In: Chernick V, Boat TF, Wilmott RW, Bush A, editors. Kendig's disorders of the respiratory tract in children. Philadelphia: Saunders Elsevier, 2006:810-838.

142. Weinberger M, Abu-Hasan M. Asthma in the preschool child. In: Chernick V, Boat TF, Wilmott RW, Bush A, editors. Kendig's disorders of the respiratory tract in children. Philadelphia: Saunders Elsevier, 2006:795-809.

143. Stutts MJ, Gatzy JT, Boucher RC. Activation of chloride conductance induced by potassium in tracheal epithelium. Pfluegers Arch 1988;411:252258 .

144. Stutts MJ, Gatzy JT, Boucher RC. Effects of metabolic inhibition on ion transport by dog bronchial epithelium. J Appl Physiol 1988;64:253-258.

145. del Rosario JF, Orenstein SR. Evaluation and management of gastroesophageal reflux and pulmonary disease. Curr Opin Pediatr 1996;8:209-215.

146. Tolia V, Wuerth A, Thomas R. Gastroesophageal reflux disease: review of presenting symptoms, evaluation, management, and outcome in infants. Dig Dis Sci 2003;48:1723-1729.

147. Platzker ACG. Gastroesophageal reflux and aspiration syndromes. In: Chernick V, Boat TF, Wilmott RW, Bush A, editors. Kendig's disorders of the respiratory tract in children. Philadelphia: Saunders Elsevier, 2006:592-609.

148. Buckley RH. Pulmonary complications of primary immunodeficiencies. Paediatr Respir Rev 2004;5(suppl A):S225-S233.

149. Hernandez M, Bastian JF. Immunodeficiency in childhood. Curr Allergy Asthma Rep 2006;6:468-474.

150. Chua F, Sly PD, Laurent GJ. Pediatric lung disease: from proteinases to pulmonary fibrosis. Pediatr Pulmonol 2005;39:392-401.

151. Camner P, Mossberg B, Afzelius BA. Evidence of congenitally nonfunctioning cilia in the tracheobronchial tract in two subjects. Am Rev Respir Dis 1975; $112: 807-809$

152. de Iongh RU, Rutland J. Ciliary defects in healthy subjects, bronchiectasis, and primary ciliary dyskinesia. Am J Respir Crit Care Med 1995;151:15591567.

153. Escudier E, Couprie M, Duriez B, et al. Computer-assisted analysis helps detect inner dynein arm abnormalities. Am J Respir Crit Care Med 2002; $166: 1257-1262$

154. Rutland J, Cox T, Dewar A, Cole P. Screening for ciliary dyskinesia-a spectrum of defects of motility and structure. Eur J Respir Dis Suppl 1983;127:71-77.

155. Schneeberger EE, McCormack J, Issenberg HJ, Schuster SR, Gerald PS. Heterogeneity of ciliary morphology in the immotile-cilia syndrome in man. J Ultrastruct Res 1980;73:34-43.

156. Sturgess JM, Chao J, Wong J, Aspin N, Turner JA. Cilia with defective radial spokes: a cause of human respiratory disease. N Engl J Med 1979; $300 \cdot 53-56$.

157. Sturgess JM, Chao J, Turner JA. Transposition of ciliary microtubules: another cause of impaired ciliary motility. N Engl J Med 1980;303:318-322.

158. Carson JL, Collier AM, Hu SCS. Acquired ciliary defects in nasal epithelium of children with acute viral upper respiratory infections. $N$ Engl J Med 1985;312:463-468

159. Rutland J, de Iongh RU. Random ciliary orientation. A cause of respiratory tract disease. $N$ Engl J Med 1990;323:1681-1684.

160. Wisseman CL, Simel DL, Spock A, Shelburne JD. The prevalence of abnormal cilia in normal pediatric lungs. Arch Pathol Lab Med 1981;105: $552-555$. 
161. Kroon AA, Heij JM, Kuijper WA, Veerman AJ, van der BS. Function and morphology of respiratory cilia in situs inversus. Clin Otolaryngol Allied Sci 1991;16:294-297.

162. Lundberg JON, Weitzberg E, Nordvall SL, Kuylenstierna R, Lundberg JM, Alving K. Primarily nasal origin of exhaled nitric oxide and absence in Kartagener's syndrome. Eur Respir J 1994;7:1501-1504.

163. Jain B, Rubenstein I, Robbins RA, Leise KL, Sisson JH. Modulation of airway epithelial cell ciliary beat frequency by nitric oxide. Biochem Biophys Res Commun 1993;191:83-88.

164. Hibbs JB Jr. Synthesis of nitric oxide from L-arginine: a recently discovered pathway induced by cytokines with antitumour and antimicrobial activity. Res Immunol 1991;142:565-569.

165. Lundberg JO, Weitzberg E. Nasal nitric oxide in man. Thorax 1999;54:947952

166. O'Callaghan C, Chilvers M, Hogg C, Bush A, Lucas J. Diagnosing primary ciliary dyskinesia. Thorax 2007;62:656-657.

167. Struben VM, Wieringa MH, Mantingh CJ, et al. Nasal NO: normal values in children age 6 through to 17 years. Eur Respir $J$ 2005;26:453-457.

168. Corbelli R, Hammer J. Measurement of nasal nitric oxide. Paediatr Respir Rev 2007;8:269-272

169. Piacentini GL, Bodini A, Peroni D, et al. Nasal nitric oxide for early diagnosis of primary ciliary dyskinesia: practical issues in children. Respir Med 2008;102:541-547.

170. Olbrich H, Horvath J, Fekete A, et al. Axonemal localization of the dynein component DNAH5 is not altered in secondary ciliary dyskinesia. Pediatr Res 2006;59:418-422.

171. Ellerman A, Bisgaard H. Longitudinal study of lung function in a cohort of primary ciliary dyskinesia. Eur Respir $J$ 1997;10:2376-2379.

172. Flume PA, O'Sullivan BP, Robinson KA, et al. Cystic fibrosis pulmonary guidelines: chronic medications for maintenance of lung health. Am J Respir crit care med 2007;176:957-969.

173. Hansell DM. Bronchiectasis. Radiol Clin North Am 1998:36:107-128.

174. Smit HJ, Schreurs AJ, Van den Bosch JM, Westermann CJ. Is resection of bronchiectasis beneficial in patients with primary ciliary dyskinesia? Chest 1996;109:1541-1544.

175. Balkanli K, Genc O, Dakak M, et al. Surgical management of bronchiectasis: analysis and short-term results in 238 patients. Eur J Cardiothorac Surg 2003;24:699-702

176. Date H, Yamashita M, Nagahiro I, Aoe M, Andou A, Shimizu N. Livingdonor lobar lung transplantation for primary ciliary dyskinesia. Ann Thorac Surg 2001;71:2008-2009.

177. Majithia A, Fong J, Hariri M, Harcourt J. Hearing outcomes in children with primary ciliary dyskinesia - a longitudinal study. Int J Pediatr Otorhinolaryngol 2005;69:1061-1064.

178. Mallarkey G, Sutherland J, editors. Disease management handbook. Auckland: Adis International, 1999.
179. Davis RM, Wagner EG, Groves T. Advances in managing chronic disease Research, performance measurement, and quality improvement are key. BMJ 2000;320:525-526.

180. Mahadeva R, Webb K, Westerbeek RC, et al. Clinical outcome in relation to care in centres specialising in cystic fibrosis: cross sectional study. BMJ 1998;316:1771-1775

181. Walters S, Britton J, Hodson ME. Hospital care for adults with cystic fibrosis: an overview and comparison between special cystic fibrosis clinics and general clinics using a patient questionnaire. Thorax 1994;49:300-306.

182. Praetorius HA, Spring KR. A physiological view of the primary cilium. Annu Rev Physiol 2005;67:515-529.

183. Dabdoub A, Kelley MW. Planar cell polarity and a potential role for a Wnt morphogen gradient in stereociliary bundle orientation in the mammalian inner ear. $J$ Neurobiol 2005;64:446-457.

184. Bartoloni L, Blouin JL, Maiti AK, et al. Axonemal beta heavy chain dynein DNAH9: cDNA sequence, genomic structure, and investigation of its role in primary ciliary dyskinesia. Genomics $2001 ; 72: 21-33$.

185. Blouin JL, Albrecht C, Gehrig C, et al. Primary ciliary dyskinesia/Kartagener syndrome: searching for genes in a highly heterogeneous disorder. $\mathrm{Am} J$ Hum Genet 2003;73(suppl):2440 (Abstract).

186. Horvath J, Fliegauf M, Olbrich $\mathrm{H}$, et al. Identification and analysis of axonemal dynein light chain 1 in primary ciliary dyskinesia patients. $\mathrm{Am} \mathrm{J}$ Respir Cell Mol Biol 2005;33:41-47.

187. Gehrig C, Albrecht C, Duriaus Sail G, et al. Primary ciliary dyskinesia: mutation analysis in dynein light chain genes mapping to chromosome 1 (HP28) and 22 (DNAL4). Eur Hum Genet Conference (Strasbourg, France) 2002:P0305 (Abstract)

188. Neesen J, Drenckhahn JD, Tiede S, et al. Identification of the human ortholog of the t-complex-encoded protein TCTE3 and evaluation as a candidate gene for primary ciliary dyskinesia. Cytogenet Genome Res 2002; 98:38-44.

189. Pennarun G, Bridoux AM, Escudier E, Amselem S, Duriez B. The human HP28 and HFH4 genes: evaluation as candidate genes for primary ciliary dyskinesia. Am J Respir Crit Care Med 2001;163:A538 (Abstract).

190. Blouin JL, Gehrig C, Armengot M, et al. DNAH3: characterization of the sequence and mutation search in patients with primary ciliary dyskinesia. Eur Hum Genet Conference (Strasbourg, France) 2002:P0304 (Abstract).

191. Zhang YJ, O'Neal WK, Randell SH, et al. Identification of dynein heavy chain 7 as an inner arm component of human cilia that is synthesized but not assembled in a case of primary ciliary dyskinesia. $J$ Biol Chem 2002;277: 17906-17915.

192. Pennarun G, Bridoux AM, Escudier E, et al. Isolation and expression of the human hPF20 gene orthologous to Chlamydomonas PF20: evaluation as a candidate for axonemal defects of respiratory cilia and sperm flagella. Am J Respir Cell Mol Biol 2002;26:362-370. 